\title{
FFTF REACTOR-CHARACTERIZATION PROGRAM: GAMMA-RAY MEASUREMENTS AND SHIELD CHARACTERIZATION
}

\author{
DISCLAIMER
}

This report was prepared as an account of work sponsored by an agency of the United States Government. Neither the United States Government nor any agency thereof, nor any of their employees, makes any warranty, express or implied, or assumes any legal liability or responsibility for the accuracy, completeness, or usefulness of any information, apparatus, product, or process disclosed, or represents that its use would not infringe privately owned rights. Reference herein to any specific commercial product, process, or service by trade name, trademark, manufacturer, or otherwise does not necessarily constitute or imply its endorsement, recommendation, or favoring by the United States Government or any agency thereof. The views and opinions of authors expressed herein do not necessarily state or reflect those of the United States Government or any agency thereof.

\section{Hanford Engineering Development Laboratory \\ W.L. Bunch \\ F.S. Moore, Jr. February 1983}

HANFORD ENGINEERING DEVELOPMENT LABORATORY

Operated by Westinghouse Hanford Company

P.O. Box 1970 Richlend, WA 99352 


\section{DISCLAIMER}

This report was prepared as an account of work sponsored by an agency of the United States Government. Neither the United States Government nor any agency Thereof, nor any of their employees, makes any warranty, express or implied, or assumes any legal liability or responsibility for the accuracy, completeness, or usefulness of any information, apparatus, product, or process disclosed, or represents that its use would not infringe privately owned rights. Reference herein to any specific commercial product, process, or service by trade name, trademark, manufacturer, or otherwise does not necessarily constitute or imply its endorsement, recommendation, or favoring by the United States Government or any agency thereof. The views and opinions of authors expressed herein do not necessarily state or reflect those of the United States Government or any agency thereof. 


\section{DISCLAIMER}

Portions of this document may be illegible in electronic image products. Images are produced from the best available original document. 


\section{FFTF REACTOR CHARACTERIZATION PROGRAM . GAMMA RAY MEASUREMENTS AND SHIELD CHARACTERIZATION}

\section{$\underline{\text { ABSTRACT }}$}

A series of experiments is to be made during the acceptance test program of the Fast Flux Test Facility (FFTF) to measure the gamma ray characteristics of the Fast Test Reactor (FTR) and to establish the performance characteristics of the reactor shield. These measurements are a part of the FFTF Reactor Characterization Program (RCP). Detailed plans have been developed for these experiments. During the initial phase of the Characterization Program, which will be carried out in the In-Reactor Thimble (IRT), both active and passive measurement methods witl be employed to obtain as much information concerning the ganma ray environment as is practical. More limited active ganma ray measurements also will be made in the Vibration open Test Assembly (VOTA). A later phase of characterization includes the irradiation of passive sensor packages in thirteen different special assemblies containing sensor pins that can be retrieved and replaced. These assemblies are nuclearly nearly identical to the standard core component that they replace. Use of these assemblies will permit relatively detailed spatial mapping of unperturbed reactions at a large number of normally inaccessible locations. This report presents plans for the garma ray and shielding-related measurements to be made as part of the Reactor Characterization Program. 


\section{TABLE OF CONTENTS}

List of Figures

Page

List of Tables

vi

A. GAMMA RAY MEASUREMENTS

viii

Introduction

A-1

1.0 Compton Recoil Gamma Ray Spectrometer Measurements

A- $1-1$

1.1 Introduction

A- - -

1.2 Spectrometer Design

$A-1-1$

1.3 Calibration of the Gamma Ray Spectrometer

$A-1-2$

1.4 Experimenta1 Procedure

A-1 -5

1.5 Expected Results

A- $7-5$

1.6 Acknowledgements

A-1 -7

1.7 References

A-1-7

2.0 Thermoluminescent Dosimeter Irradiation

A-2-1

2.1 Introduction

$A-2-1$

2.2 Selection of TLD Material

A-2-1

2.3 Design of Experiment

A-2-1

2.4 Expected Results

A-2-3

2.5 Acknowledgements

A-2-3

A-3-1

3.0 IRT Ionization Chambers

A-3-1

3.1 Introduction

A-3-1

3.2 Design of Chambers

A-3-2

3.3 Calibration and Instrumentation

A-3-7

3.4 Proposed Experiment

A-3-7

3.5 Expected Results

A-3-8

3.6 Acknowledgement

A-3-8

3.7 Reference

A-4-1

4.0 IRT Adiabatic Calorimeter

A-4-1

4.1 Introduction

A-4- 1

4.2 Basis for Design

A-4-2

4.3 Design and Construction of Calorimeter 


\section{TABLE OF CONTENTS}

(Continued)

4.4 Calibration and Operation of the Calorimeter

Page

4.5 Proposed Experiment

A-4-4

4.6 Expected Results

A-4-4

4.7 Acknowledgements

A-4-7

4.8 References

A-4-7

A-4-8

5.0 VOTA Ionization Chambers

5.1 Introduction

5.2 Design and Construction of VOTA Ion Chambers

5.3 Calibration and Instrumentation

A-5-5

5.4 Proposed Experiment

A-5-9

5.5 Expected Results

A-5-9

5.6 Acknowledgements

A-5-10

6.0 VOTA Self-Powered Gamma Ray Detector

A $-6-1$

6.1 Introduction

A-6-1

6.2 Design and Construction of Detector

$A-6-1$

6.3 Calibration and Instrument System

A-6-3

6.4 Proposed Experiment

A-6-3

6.5 Expected Results

A-6-5

6.6 Acknowledgements

A-6-5

6.7 Reference

A-6-5

A-7-1

7.0 VOTA Whitshell Calorimeters

7.1 Introduction

7.3 Calibration and Operation of the Whitshell

A-7-2 Calorimeter

A-7-4

7.4 Proposed Experiment

A-7-7

7.5 Expected Results

A-7-7

7.6 Acknowledgements

7.7 Reference 


\section{TABLE OF CONTENTS}

(Continued)

8.0 VOTA HEDL Calorimeters

Page

8.1 Introduction

A-8-1

8.2 Design and Construction of the HEDL Calorimeter

A-8-1

8.3 Calibration of the HEDL Calorimeters

A-8-1

8.4 Experiment

$A-8-3$

8.5 Expected Results

A-8-4

8.6 Acknowledgements

$A-8-4$

8.7 References

$A-8-4$

$A-8-5$

9.0 Thermal Expansion Difference Detectors A-9-1

9.1 Introduction

9.2 Design and Construction

9.3 Calibration of TED Detectors

$A-9-3$

9.4 Proposed Experiment

$A-9-3$

9.5 Expected Results

A-9-3

9.6 Reference

A-9-5

B. SHIELD CHARACTERIZATION

Introduction

$B-1$

1.0 Characterizer Irradiations

1.1 Introduction

1.2 Design of Characterizers

1.3 Proposed Experiment

1.4 Expected Results

$B-1-7$

1.5 Acknowledgements

$\mathrm{B}-1-8$

2.0 In-Vessel Storage Measurements

$B-2-1$

2.1 Introduction

2.2 Design of Sample Holder

$\mathrm{B}-2-2$

2.3 Proposed Experiment

$B-2-2$

2.4 Expected Results

B-2-4

2.5 Acknowledgements

B-2-4 


\section{TABLE OF CONTENTS}

(Continued)

3.0 Reactor Cavity Measurements

Page

3.1 Introduction

B-3-1

3.2 Design of Detection System

B-3-1

3.3 Proposed Experiment

$B-3-1$

3.4 Expected Results

$B-3-4$

3.5 Acknowledgements

$B-3-6$

B-3-6 


\section{FIGURES}

Number

Page

A. GAMMA RAY MEASUREMENTS

1.1 Cross-Sectional View of the Janus Detector Configuration

$A-1-3$ and Block Diagram of the Pulse Processing Instrumentation

1.2 Relative Coincidence Janus Probe Pulse-Height Spectral

Response Due to Monoenergetic 4.44 and 6.13 MeV Gamma Rays

1.3 Calculated Gamma Ray Spectra In Core and Reflector

$A-1-6$

2.1 TLD Sample Holder

A-2-2

2.2 Total Flux Above Core Center, Row 2

A-2-4

2.3 Total Flux Below Core Center, Row

$A-2-5$

3.1 304 Stainless Steel Bragg-Gray Chamber Typical Assembly

A-3-4

3.2 Electronics Arrangement

$A-3-5$

4.1 Calorimeter for the In-Reactor Thimble

A-4-3

4.2 Assembly \#3 Trial Run

A-4-5

4.3 Schematic Representation of Calorimeter and Temperature Measurement Instrumentation

A-4-6

5.1 Vibration Open Test Assembly (VOTA)

A-5-4

5.2 Data Acquisition for In Situ Gamma Ionization Chamber A-5-6 Tests

5.3 Block Diagram of HEDL ${ }^{60}$ Co Facility and Associated Data Acquisition Equipment

A-5-7

5.4 Block Diagram of BNW Open Air ${ }^{60}$ Co Facility and Associated Data Acquisition Equipment

6.1 Vendor Supplied As-Built Drawing for the Platinum Detectors

6.2 Gamma Measurement Block Diagram

$A-5-8$

A-6-2

7.1 Whitshe11 High Temperature Calorimeter, Line Drawing

A-6-4

7.2 Temperature Vs Transient Time During Calibration for

A-7-3 Whitshell Calorimeter No. 2, Run No. 3

7.3 Sample Cooling Rate Vs $\Delta T$ Between Sample and Jacket, Calorimeter No. 2, Run No. 3

8.1 VOTA Calorimeter

A-7-5

9.1 Thermal Expansion Difference Temperature Monitor Assembly

A-8-2

9.2 Calibration of TED Batches H-M (August 1977)

A-9-2 


\section{FIGURES}

(Continued)

Number

$\underline{\text { Page }}$

B. SHIELD CHARACTERIZATION

1.1 Core Characterizer Rows $1-6$ and In-Core-Shim B-1-2

1.2 Rows 7 and $8 A$ Characterizer B-1-3

1.3 Rows $8 B$ and 9 Characterizer B-1-4

1.4 Sensor Pin Plan B-7-5

1.5 Relative Positions of Sensors in Characterizers, B-1-6 In-Vessel Storage Module, and Reactor Cavity Thimble

$\begin{array}{ll}\text { 2.1 In-Vessel Storage - Sample Holder - Partial View } & B-2-3 \\ 3.1 & \text { Reactor Cavity } \\ \text { B.3-2 }\end{array}$

3.2 Reactor Cavity Sensor Holder B-3-3

3.3 Location of Storage Module with Respect to Reactor B-3-5 Cavity Thimble 


\section{$\underline{\text { TABLES }}$}

Number

Page

A. GAMMA RAY MEASUREMENTS

1.1 Gamma Ray Calibration Sources

A-1-4

3.1 Physical Parameters of IRT Ionization Chambers

A-3-3

3.2 Calibration Factors for Ionization Chambers

A-3-6

5.1 Reuter Stokes Detector Specifications

A-5-2

5.2 Westinghouse Detector Specification

A-5-3

B. SHIELD CHARACTERIZATION

None 
GLOSSARY OF ACRONYMS

$\begin{array}{ll}\text { CH } & \text { Characterizer } \\ \text { CLEM } & \text { Closed Loop Ex-Vessel Machine } \\ \text { EVFM } & \text { Ex-Vessel Flux Monitor } \\ \text { FFTF } & \text { Fast Flux Test Facility } \\ \text { FTR } & \text { Fast Test Reactor } \\ \text { HEDL } & \text { Hanford Engineering Development Laboratory } \\ \text { IRT } & \text { In-Reactor Thimble } \\ \text { IVS } & \text { In-Vessel Storage } \\ \text { IVS-SH } & \text { In-Vessel Storage Sample Holder } \\ \text { LLFM } & \text { Low Level Flux Monitor } \\ \text { PNL } & \text { Pacific Northwest Laboratory } \\ \text { RCP } & \text { Reactor Characterization Program } \\ \text { RTD } & \text { Resistance Temperature Detectors } \\ \text { SSTR } & \text { Solid State Track Recorders } \\ \text { TED } & \text { Thermal Expansion Difference } \\ \text { TLD } & \text { Thermoluminescent Dosimeters } \\ \text { VOTA } & \text { Vibration Open Test Assembly } \\ \end{array}$




\section{A. GAMMA RAY MEASUREMENTS}

\section{INTRODUCTION}

The Fast Flux Test Facility (FFTF) includes the sodium-cooled Fast Test Reactor (FTR) that is designed to irradiate breeder reactor fuels and materials under prototypic temperature and flux conditions. Although neutrons are of primary importance in operation of the reactor and in establishing radiation damage rates, the gamma ray environment is also important. The gamma ray field is the primary source of energy deposited in structural materials and in establishing material operating temperatures. Radiation damage is known to be strongly temperature dependent; therefore, it is essential that the gamma ray environment be known, both to support the design of material tests and to evaluate the results of such tests. In addition, the gamma ray distribution is required to establish the power deposition distribution throughout the reactor in order that operational parameters might be appropriately maintained. For these reasons, a gamma ray characterization program was formulated that would measure the environment with sufficient accuracy to meet the irradiation goals of the facility. The gamma ray measurements program consists of three different parts, each of which utilizes special test vehicles. All parts of the program are to be completed prior to the start of routine operation of the reactor.

The first part of the program will consist of measurements to be made at very low power levels using access through the reactor core provided by the In-Reactor Thimble (IRT). The thimble is to be located adjacent to the central core position and permit measurements to be made in a gas atmosphere (rather than sodium) at room temperature. The gamma flux measurements are to include the use of three different ionization chambers, one calorimeter, a large number of thermoluminescent dosimeters, and a gamma ray spectrometer. This use of a large variety of sensors is to minimize the potential that a common bias could compromise the accuracy of the results. The use of a large number of active and passive sensors is made possible by the existence of the IRT.

The second part of the program will consist of ionization chamber and calorimeter measurements at intermediate and high power levels in the 
Vibration Open Test Assembly (VOTA). The VOTA will be located in row six, which is the last row of fuel adjacent to the inconel-rich reflector assemblies. Diverse sensors will also be employed in the VOTA to minimize the potential for a common measurement bias. The sensors include two different types of calorimeters, ionization chambers from two different sources, and self-powered gamma detectors.

The third part of the gamma ray measurements program will consist of the use of Thermal Expansion Difference (TED) detectors while the reactor is operated at full power. The TED detectors will be located within sensor pins which are in turn positioned within special core components called Characterizers $(\mathrm{CH})$. From the nuclear standpoint, the Characterizers are essentially identical to the core component that they replace (fuel, shim or reflector assembly). However, the Characterizers are designed to permit removal and replacement of the sensor pins. The TED detectors will provide a relatively detailed mapping of the peak temperature throughout the core and, therefore, an indication of the power deposition and gamma ray distribution.

The gamma ray source distribution associated with a reactor is directly related to the neutron flux distribution and contains both a prompt and delayed component. The delayed component is obviously dependent on past operating history and includes material activation as well as fission product activity. Thus, it is essential that the gamma ray measurements program be carried out in a systematic manner to obtain as much detai1 as possible on the prompt and delayed components. The initial, low power measurements will be aimed at measuring the prompt component; whereas, the subsequent measurements will provide additional information on the production and decay of the delayed gamma ray sources.

The following sections describe each of the planned gamma ray measurements in some detail. Within the limitations of state-of-the-art detectors, this gamma ray measurements program is intended to define the intensity and spectral distribution throughout the reactor with accuracies of the order of $5 \%$ to $10 \%$. Results of the measurements will be used together with analyses to support operation of the reactor and the material test program. 


\subsection{COMPTON RECOIL GAMMA RAY SPECTROMETER MEASUREMENTS}

\subsection{Introduction}

Gamma ray calculations in a reactor are a multi-step process. First, the neutron flux distribution must be calculated. Next, the gamma ray source distribution is calculated by the product of the neutron flux and the appropriate gamma ray production cross sections, considering spatial material composition as well as both neutron and gamma ray energy distribution. Using the ganma ray source, the gamma ray flux can then be calculated by considering the transport of the photons throughout the system. Given the gamma ray flux distribution, the gamma ray heating or energy deposition rate can be calculated. Most gamma ray sensors have a response that is related to the energy deposition rate. A knowledge of the gamma ray spectrum would provide significant additional insight into the validity of the calculations.

Historically, very little emphasis was placed on the measurement of the gamma ray environment in a reactor, primarily because fission reactors are dependent on the neutron chain reaction. As greater knowledge has been obtained concerning the behavior of materials, the importance of gamma rays was recognized. In addition, the development of solid state compton recoil gamma spectrometers makes measurements within a core possible. $[1]$

\subsection{Spectrometer Design}

The gamma ray spectrum is to be measured using a Compton recoil gamma ray spectrometer. Operation of this spectrometer is analogous to that of a proton recoil spectrometer. The recoil electron continuum induced in the detector by the gamma ray spectrum is recorded. The gamma ray spectrum is then inferred by unfolding this continuum based on the response of the systern to monoenergetic gamma sources.

A number of significant improvements in the state-of-the-art have been incorporated in the design of the Compton recoil spectrometer for use in the FTR measurements. A significant limitation on the resolution and dynamic range of Compton spectrometers has been the sensitivity of the 
detector to events in which the Compton scattering takes place within the sensitive volume of the detector, and the recoil electron either exits the Silicon detector or deposits some of its energy in the semisensitive and dead layers of the detector. This has been overcome with the development of the "Janus" probe, which employes two Si(Li) detectors placed face to face. Acquiring both energy and rise time information for each pulse allows discrimination between pulses resulting from total energy deposition within the sensitive volume. The two detectors face to face, when operated in the coincidence mode, effectively double the size of the detector extending the energy range of the system without the increase in leakage current noise found in a single layer crystal. Operated in the anticoincidence mode the two detectors enhance low energy gamma resolution. To minimize the leakage current the detectors are mounted on a Peltier refrigerator. A schematic diagram of the Janus probe and its associated electronics is shown in Figure 1.1. By using coincidence and anticoincidence modes of operation, this sytem is expected to provide gamma ray energy measurements from about $0.2 \mathrm{MeV}$ up to $7 \mathrm{MeV}$ or more. This is a significantly greater range than the current $3 \mathrm{MeV}$; and if successful, will provide valuable information for FTR.

\subsection{Calibration of the Gamma Ray Spectrometer}

The elementary response of the system to monoenergetic gamma rays was determined principally with radioisotopic sources. Table 1.1 contains a list of gamma rays that can be used, listed in order of increasing energy.

The Janus probe coincidence mode response for $4.44 \mathrm{MeV}$ and $6.13 \mathrm{MeV}$ gamma rays is shown in Figure 1.2. The high energy response for the $4.44 \mathrm{MeV}$ gamma ray can be seen to be quite good, with a sharp well-defined Compton edge. On the other hand, the Compton edge of the $6.13 \mathrm{MeV}$ gamma ray is not nearly as well defined, apparently because of the increased effect of electron escape from the probe. 


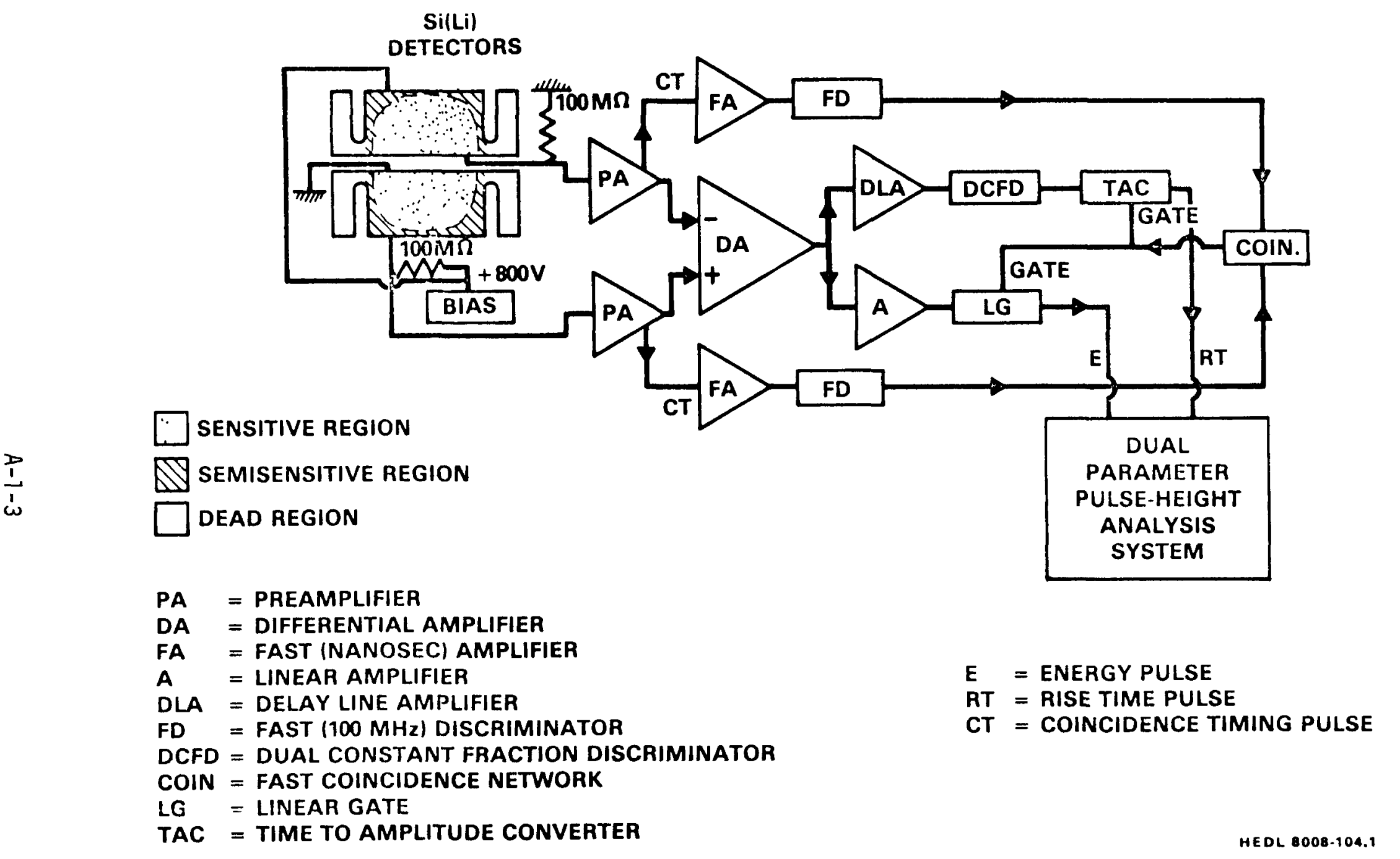

Figure 1.1. Cross sectional view of the Janus detector configuration and block diagram of the pulse processing instrumentation. 
Table 1.1

GAMMA RAY CALIBRATION SOURCES

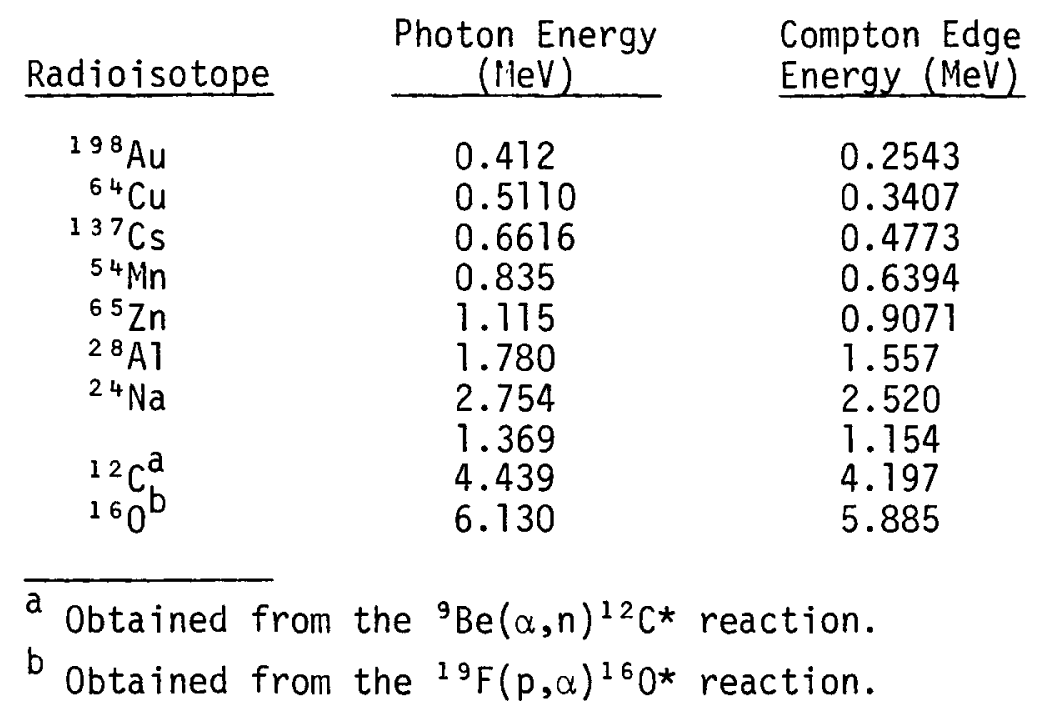

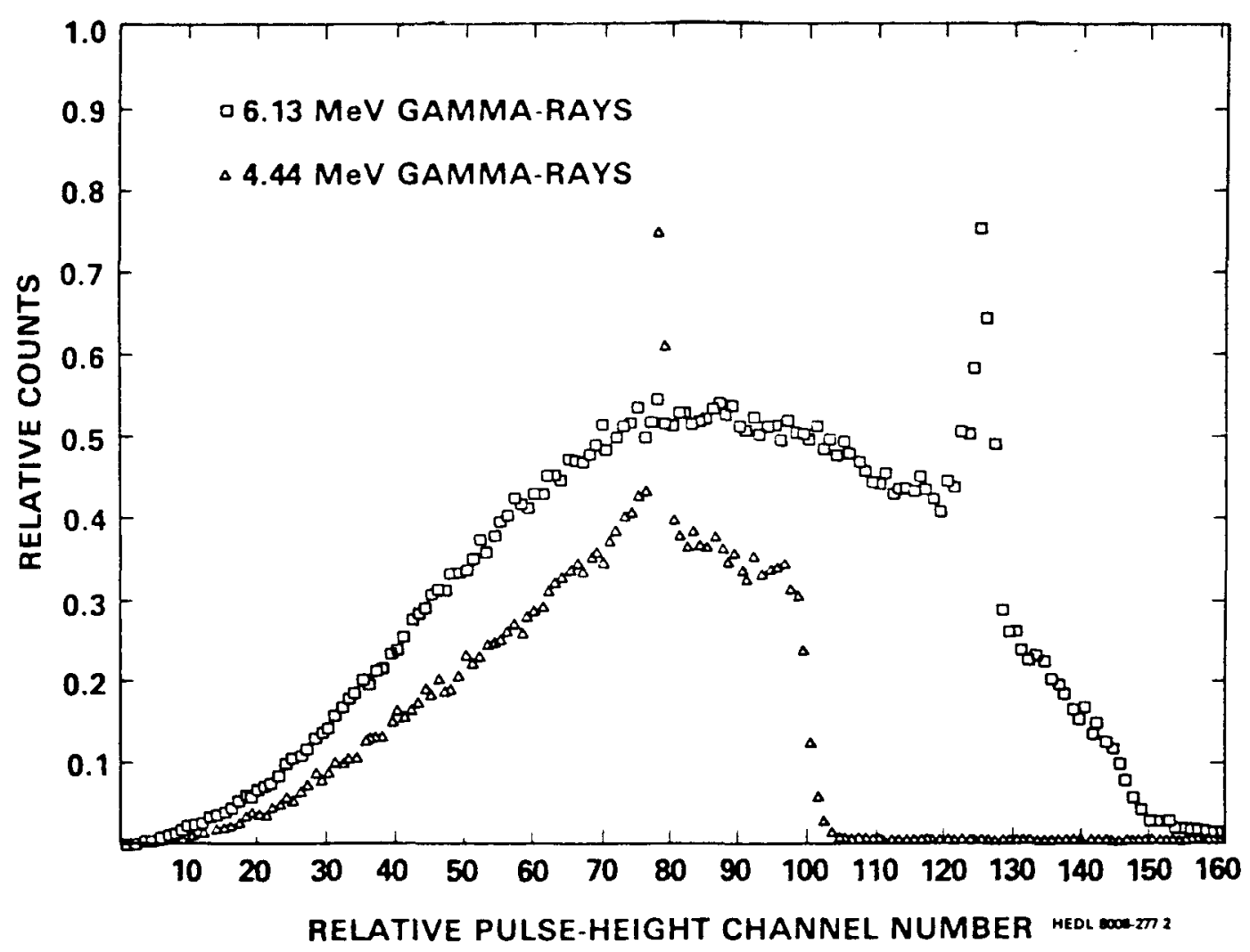

Figure 1.2. Relative coincidence Janus probe pulse-height spectral response due to monoenergetic 4.44 and $6.13 \mathrm{MeV}$ gamma rays. 
An interesting effect arises in the response of the detectors at higher energy, as illustrated in Figure 1.2. While the Compton interaction still dominates, a distinct double-escape peak from pair production is also clearly observable. Since pair production increases with gamma ray energy, this effect must be accounted for in attempting to interpret the data; otherwise, spurious peaks could be introduced into the gamma continuum through the unfolding process. Additional effort needs to be expended in this area.

\subsection{Experimental Procedure}

The spectrometer measurements will be made with the reactor subcritical and prior to the time the reactor has been taken to power to generate a significant background from decay products. Two measurements will be required at each location. The first will be made with the control rods fully inserted to provide a measure of the background. Then, control rods will be withdrawn to increase the multiplication factor of the system to achieve a suitable count rate signal on the spectrometer. Even though the reactor will be subcritical, the prompt signal will be much greater than the decay background. Thus, the difference between the measurements will be associated with the prompt gamma ray spectrum.

The gamma ray spectrum will be measured at the core midplane elevation and also outside the fuel region. The count rate data obtained from the electron recoil energy distribution will be stored on magnetic tape for subsequent processing. Existing unfolding codes are based on theoretical interpretation of monoenergetic response functions. If the detector is successful in recording events for gamma rays with energy significantly greater than about $3 \mathrm{MeV}$, it will be necessary to obtain additional calibration data at these energies to provide a basis for unfolding the spectrum.

\subsection{Expected Results}

Figure 1.3 presents results of calculations of the gamma ray spectrum both in the core and in the reflector region of the FTR. These spectra are based on results of three-dimensional diffusion theory calculations. To 


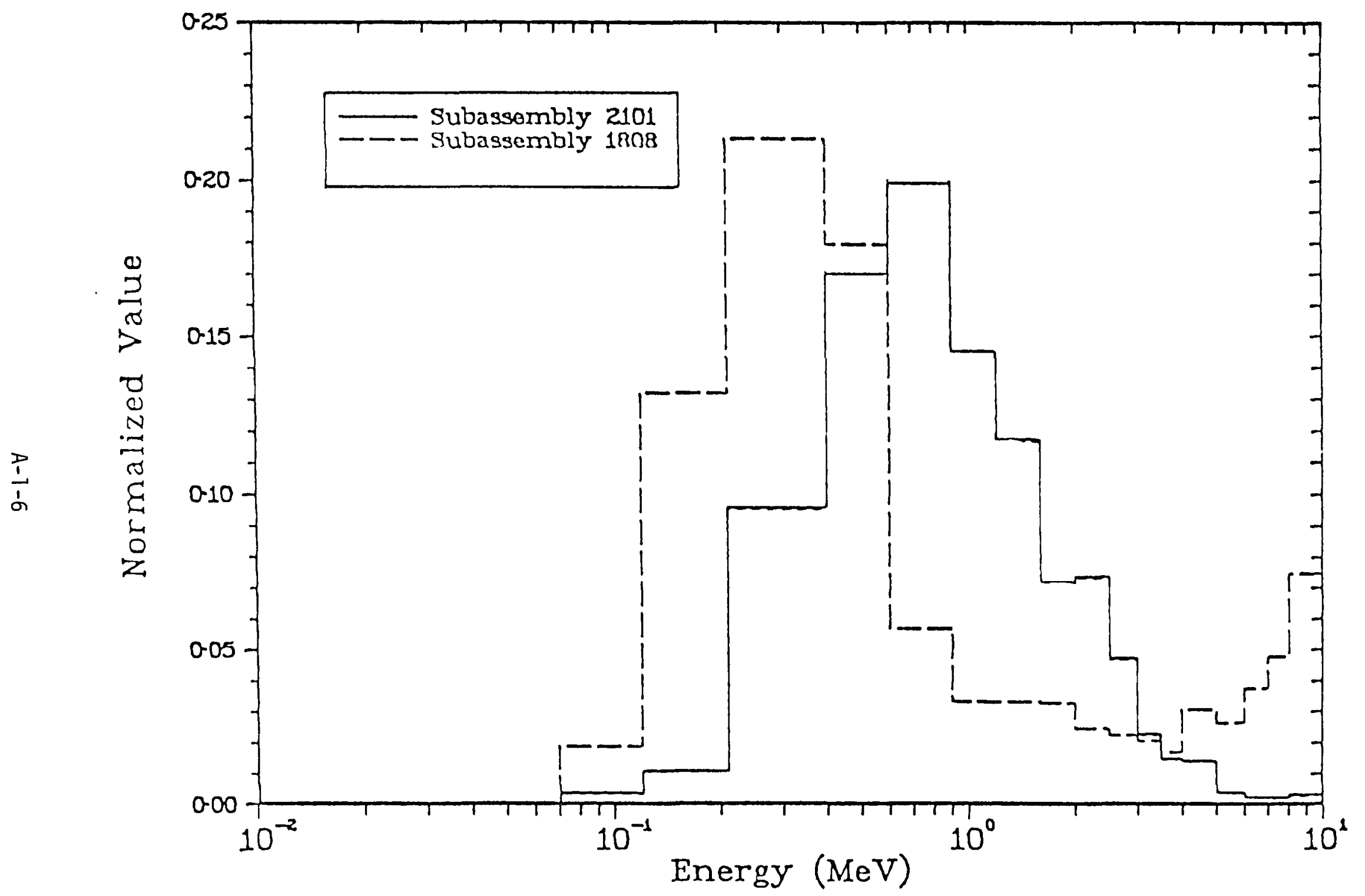

Figure 1.3. Calculated gamma ray spectra in core and reflector. 
calculate the gamma ray spectrum, it is first necessary to obtain the neutron distribution because the gamma ray source is directly related to the neutron flux. The spatial and energy distribution of the neutron flux is then folded together with gamma ray production cross sections, and a fixed gamma ray source is then run to obtain the gamma ray flux distribution in both space and energy. Calculations to date have employed 42 neutron groups and 18 energy groups. It is anticipated that the resolution of the gamma ray spectrometer will be much better than that provided by the 18 energy groups. This will probably require that additional calculations be undertaken to resolve differences that are seen. Gross discrepancies between the measured and calculated spectra are expected to provide a basis for improving the nuclear data base for gamma ray calculations in the reactor.

\subsection{Acknowledgments}

The design and development of the Compton recoil gamma ray spectrometer was carried out by Dr. Raymond Gold and Dr. Bruce J. Kaiser. Dr. Gold is a pioneer in the application of the Compton recoil method to measure the gamma ray spectrum in a fast reactor environment and was responsible for having the measurements included in the currently planned Reactor Characterization Program. Much of the electronic improvisation is attributed to Dr. Kaiser, who was largely responsible for developing an operational system with the extended energy capabilities.

\subsection{References}

1. R. Gold and B. J. Kaiser, "Status of Compton Recoil Gamma-Ray Spectroscopy," Trans. Am. Nucl. Soc., 33, 692 (1979). 


\subsection{THERMOLUMINESCENT DOSIMETER IRRADIATION}

\subsection{Introduction}

When a thermoluminescent phosphor is exposed to ionizing radiation, many of the freed electrons become trapped at lattice imperfections and will remain trapped for long periods of time when stored at low temperatures. When the temperature of the material is raised, the electrons are released and return to the stable state with the emission of light. Under controlled conditions the amount of light emitted is a measure of the integrated dose received. Because of their small size, the thermoluminescent dosimeters (TLD) provide a method of obtaining relatively detailed spatial distribution measurements without materially perturbing the environment being measured.

\subsection{Selection of TLD Material}

A number of different materials have been used for gamma ray measurements, including lithium fluoride, calcium sulfate, and calcium fluoride. Lithium fluoride is widely used for personnel dosimeters because its electron density and response is comparable to that of tissue. Manganese-activated calcium fluoride is to be used in the FTR measurements because its electron density and response more nearly resemble that of the iron in which it is to be placed. Thus, the dose received by the TLD will provide a direct measure of the dose that would have been received by an iron sample at that location, with only relatively small correction factors being required to account for differences in the materials.

\subsection{Design of Experiment}

The special insert for irradiating the TLD material in the In-Reactor Thimble (IRT) will consist of a fifteen foot long iron bar. The iron bar is made of relatively pure magnet iron in order to minimize the production of ${ }^{56} \mathrm{Mn}$ which could potentially create needlessly high radiation levels. Design of the iron bar is given in drawing H-4-61179. The iron bar is approximately 2.375 inches in diameter and contains 55 holes that are 0.5 inches in diameter and spaced approximately 2 inches apart. Cylindrical plugs (see Figure 2.1) screw into each of the 55 holes, with each 
plug containing five TLDs. Each TLD is a parallelepiped approximately one millimeter by one millimeter and six millimeters long. The large number of TLDs will provide a relatively detailed radial mapping across the iron bar as well as providing the axial distribution of the gamma ray energy deposition.
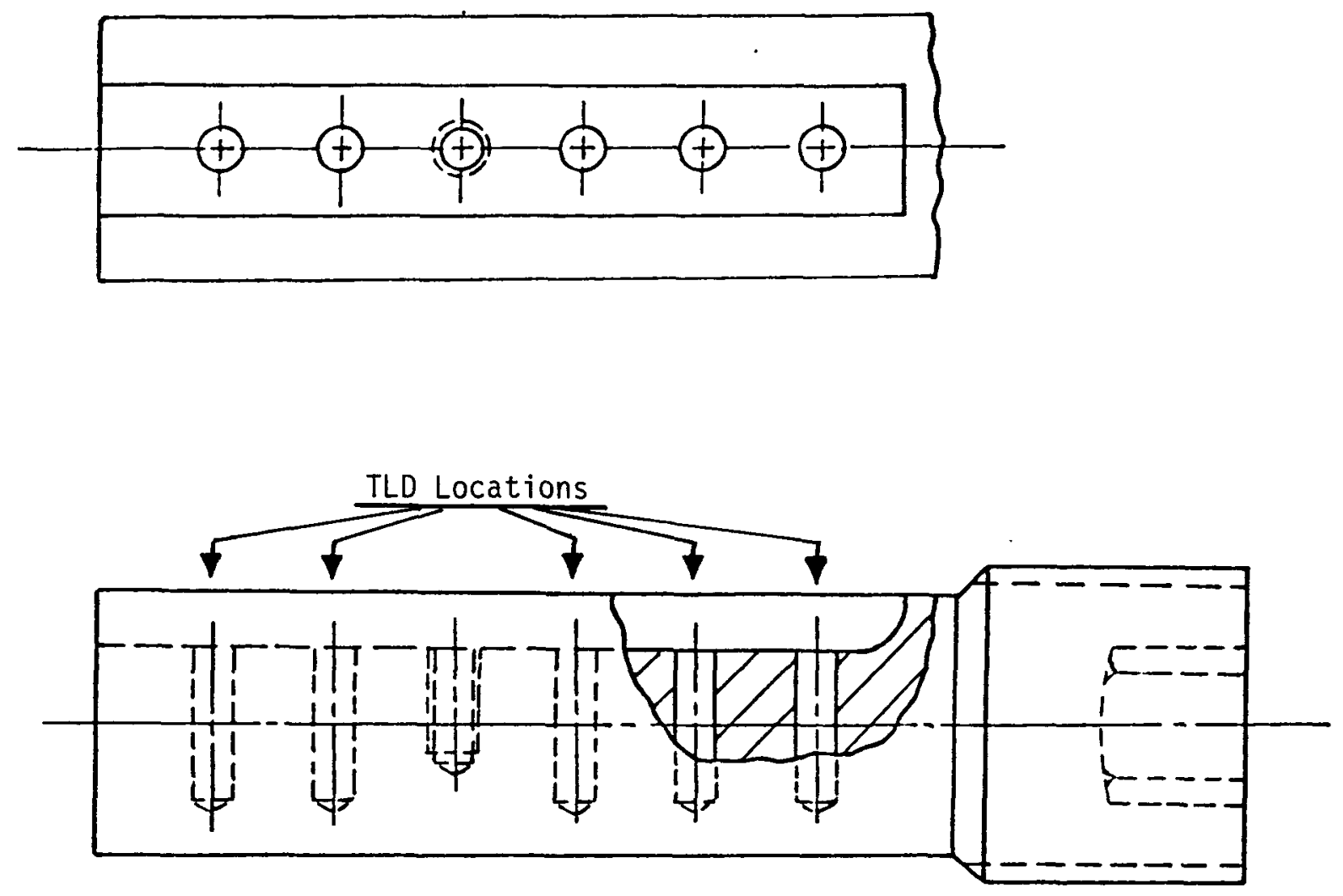

Figure 2.1. TLD sample holder.

Five of the trays will have tungsten inserts placed around the TLD. These trays will be placed within the core region to provide energy deposition in tungsten as well as in iron. This is of interest for comparison with the ionization chamber measurements, which will also be made with steel and tungsten wall materials.

Each of the TLDs used in the experiment will be selected to assure uniformity of response. This selection process will be accomplished by 
preirradiating the TLDs to the same dose and then processing to select those whose response is within defined limits. A set of TLDs will also be created for use in obtaining calibration data. Calibration will be based on response to a cobalt source of known intensity. The TLD reader is a standard commercial device built for this purpose.

\subsection{Expected Results}

Figures 2.2 and 2.3 present results of two- and three-dimensional diffusion theory calculations of the axial distribution of the gamma ray flux. The axial spacing of the mesh points in the calculation corresponds closely with the axial spacing of the TLDs to be irradiated in the FTR; therefore, a ready comparison will be possible. Very little radial detail is obtained in these calculations. Each lattice position of the reactor is simulated in the calculation by six triangles, and the radial composition of each lattice position is uniform. Additional calculations will be required to investigate the expected radial detail across the iron bar. Since the IRT will be located near the center of the core, the radial distribution through the bar should be nearly symmetric. It is possible that a Monte Carlo calculation will be required for interpretation of the radial data.

\subsection{Acknowledgments}

The authors wish to acknowledge the useful discussions with Dr. Gale Simons of Kansas State University, who has previously employed TLD materials to measure the gamma ray distribution in critical facilities. 


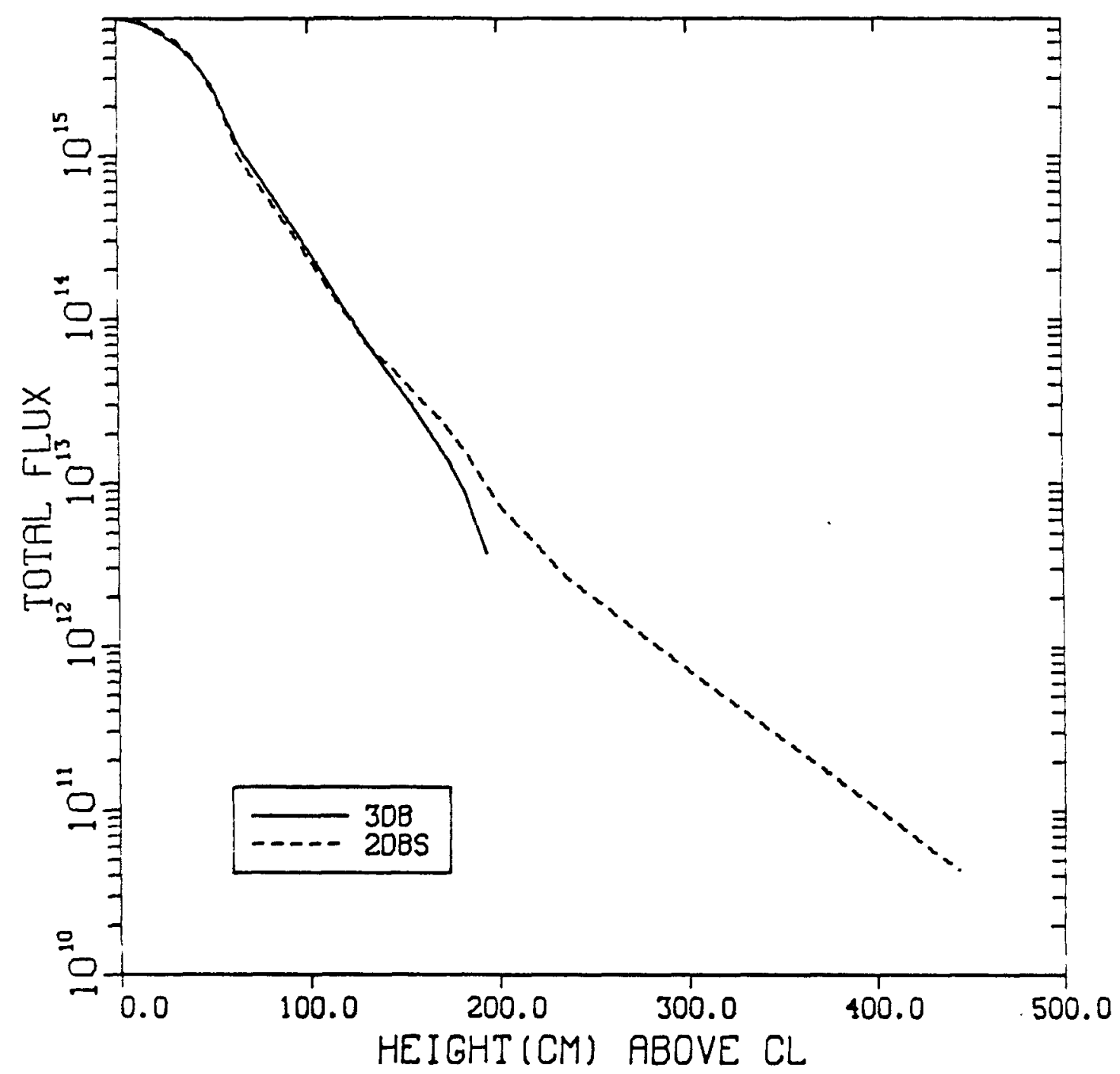

Figure 2.2. Total flux above core center, row 2. 


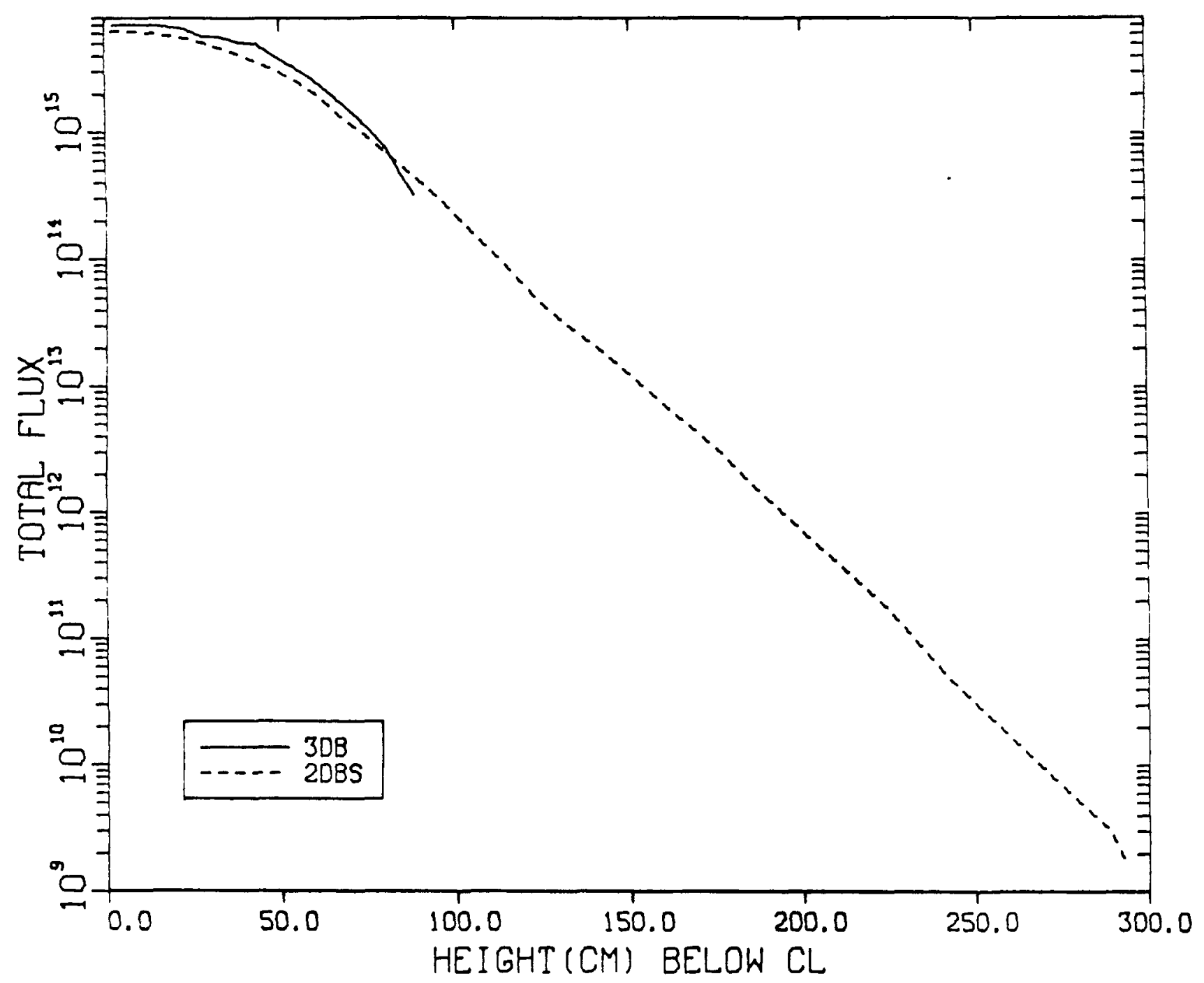

Figure 2.3. Total flux below core center, row 2 . 


\subsection{IRT IONIZATION CHAMBERS}

\subsection{Introduction}

Ionization chambers provide a well established method of measuring the gamma ray field based on the Bragg-Gray theory of ionization in a cavity. [1] The quantity of interest is $\mathrm{dE} / \mathrm{dm}$, the rate of energy absorption per unit mass. The mechanism of energy absorption is energy transfer from the primary radiation beam, in this case gamma radiation, by ionization in the medium. The Bragg-Gray theory states that under certain assumptions the energy deposited within a gas filled cavity is a measure of the energy deposited within the surrounding material. These assumptions are equivalent to the statement that the chamber must be a negligible perturbation on the equilibrium ionization field produced by the incident gamma radiation.

Ionization chambers intended for spatial distribution measurements of absorbed dose in a particular medium must satisfy specific conditions basic to cavity theory. These conditions impose limits on the dimensions of the wall and cavity as well as on the materials. When appropriately constructed, an ionization chamber provides a measure of the absorbed dose in the wall material. By using various wall materials, additional information can be learned about the gamma ray environment; and when coupled with other measurements and calculations, will provide a more accurate knowledge of the gamma ray field throughout the reactor.

\subsection{Design of Chambers}

For the IRT ion chambers the conditions discussed above were satisfied as follows. Examination of calculated gamma spectra (Figure 1.3) showed that the intensity of gammas with energies in excess of $3 \mathrm{MeV}$ is very small. Hence, a wall thickness corresponding to the mean free path of a $3 \mathrm{MeV}$ gamma was chosen. In this way, the medium is infinite for electrons produced by gammas of energy less than $3.25 \mathrm{MeV}$. The attenuation of the primary gamma field in this wall thickness is small and may easily be corrected for in the data analysis. The inner diameter of the chamber was chosen such that the diameter of the chamber was small compared to the range of an electron in the gas. The fill gas chosen was argon, a good match to the range of atomic numbers chosen for the wall materials. 
Three different types of ionization chambers were designed and fabricated for use in the IRT measurements by Dr. Bruce Kaiser of the Instrument Development group at the Hanford Engineering Development Laboratory (HEDL). The wall materials selected were graphite, steel and tungsten which have atomic numbers of 6,26 (iron) and 74, respectively. Energy dependent gamma ray cross sections vary strongly with the atomic number; therefore, the differing responses of these materials should provide some insight into the validity of the energy dependence of the gamma ray calculations as well as the absolute magnitude.

The chambers were cleaned, assembled, outgassed and pumped down to a pressure of $10^{-8}$ microns before being filled simultaneously to a pressure of 761 torr with argon. Table 3.1 gives the significant dimensions of the chambers, and Figure 3.1 shows a typical chamber. Because of the size requirements introduced by the wall material, the graphite chambers were significantly larger in diameter than the steel and tungsten chambers. The latter two chambers are small enough in diameter to use with the IRT traversing mechanism; whereas, three graphite walled chambers will be located in the instrument canister at three different elevations. This will limit the graphite chamber data to three discrete points, while the other two chambers will be traversed a total distance of 7 feet, approximately centered at core midplane.

\subsection{Calibration and Instrumentation}

A schematic diagram of the instrumentation system for the chamber measurements is illustrated in Figure 3.2. This figure shows the arrangement for the traversing experiment. Data are collected by the HP-9825 system, which records the data on magnetic tape for future analysis as well as providing a printout of the data. The current from the reactor Low Level Flux Monitor (LLFM) "A" chamber will be the chamber data to allow correcting for any drifts in the reactor power during the data collection period. The output of the traverse height indicator on the IRT traversing mechanism will also be recorded at each data point to provide elevation information. The data collection system for the graphite chamber experiment is similar except that the traverse height signal is not used; and three, rather than one, ion chamber signals are fed into the 9825 , where 
Table 3.1

PHYSICAL PARAMETERS OF IRT IONIZATION CHAMBERS

\begin{tabular}{|c|c|c|c|c|c|c|c|c|c|c|}
\hline \multirow[t]{2}{*}{ Detector } & \multirow{2}{*}{$\begin{array}{l}\text { Material } \\
\text { Type }\end{array}$} & \multicolumn{4}{|c|}{ Outer Sheath } & \multirow{2}{*}{\multicolumn{2}{|c|}{$\begin{array}{l}\text { Sensitive } \\
\text { Length }\end{array}$}} & \multirow{2}{*}{$\begin{array}{l}\text { Capacitance } \\
\text { (pf) }\end{array}$} & \multirow{2}{*}{$\begin{array}{l}\text { Resistance } \\
\quad\left(10^{12} \Omega\right)\end{array}$} & \multirow{2}{*}{$\begin{array}{c}\text { Sensitivity } \\
10^{-12} \frac{\mathrm{amp}}{\mathrm{R} / \mathrm{hr}} \\
\end{array}$} \\
\hline & & 0. & & (in) & $\overline{(\mathrm{cm})}$ & & & & & \\
\hline CK-2 & *Carbon & 0.796 & 2.02 & 0.197 & 0.5 & 2.0 & 5.08 & 10.4 & 20 & 0.101 \\
\hline CK-3 & *Carbon & 0.796 & 2.02 & 0.197 & 0.5 & 2.0 & 5.08 & 10.6 & 3 & 0.101 \\
\hline CK-4 & *Carbon & 0.796 & 2.02 & 0.197 & 0.5 & 2.0 & 5.08 & 10.3 & 16 & 0.101 \\
\hline SK-1 & 304 SS & 0.396 & 1.00 & 0.197 & 0.5 & 2.0 & 5.08 & 10.7 & 20 & 0.122 \\
\hline TK-1 & Tungsten & 0.306 & 0.777 & 0.197 & 0.5 & 2.0 & 5.08 & 11.4 & 5 & 0.176 \\
\hline
\end{tabular}

* Carbon is Poco Graphite HPD-1 with an average density of $1.818 \mathrm{gms} / \mathrm{cm}^{3}$.

All chambers were filled simultaneously to 761 Torr with $99.99995 \%$ pure argon. 
Table 3.1

PHYSICAL PARAMETERS OF IRT IONIZATION CHAMBERS

\begin{tabular}{|c|c|c|c|c|c|c|c|c|c|c|}
\hline \multirow[t]{2}{*}{ Detector } & \multirow[t]{2}{*}{$\begin{array}{c}\text { Material } \\
\text { Type }\end{array}$} & \multicolumn{4}{|c|}{ Outer Sheath } & \multicolumn{2}{|c|}{$\begin{array}{l}\text { Sensitive } \\
\text { Length }\end{array}$} & \multirow[t]{2}{*}{$\begin{array}{c}\text { Capacitance } \\
(\mathrm{pf})\end{array}$} & \multirow[t]{2}{*}{$\begin{array}{c}\text { Resistance } \\
\left(10^{12} \Omega\right)\end{array}$} & \multirow{2}{*}{$\begin{array}{c}\text { Sensitivity } \\
10^{-12} \mathrm{amp} \\
\frac{\mathrm{R} / \mathrm{hr}}{}\end{array}$} \\
\hline & & $(\mathrm{in})$ & $(\mathrm{cm})$ & (in) & $(\mathrm{cm})$ & in & $(\mathrm{cm})$ & & & \\
\hline$C K-2$ & *Carbon & 0.796 & 2.02 & 0.197 & 0.5 & 2.0 & 5.08 & 10.4 & 20 & 0.101 \\
\hline$C K-3$ & *Carbon & 0.796 & 2.02 & 0.197 & 0.5 & 2.0 & 5.08 & 10.6 & 3 & 0.101 \\
\hline CK-4 & *Carbon & 0.796 & 2.02 & 0.197 & 0.5 & 2.0 & 5.08 & 10.3 & 16 & 0.101 \\
\hline SK-1 & 304 SS & 0.396 & 1.00 & 0.197 & 0.5 & 2.0 & 5.08 & 10.7 & 20 & 0.122 \\
\hline $\mathrm{TK}-1$ & Tungsten & 0.306 & 0.777 & 0.197 & 0.5 & 2.0 & 5.08 & 11.4 & 5 & 0.176 \\
\hline
\end{tabular}

* Carbon is Poco Graphite HPD-1 with an average density of $1.818 \mathrm{gms} / \mathrm{cm}^{3}$.

A11 chambers were filled simultaneously to 761 Torr with $99.99995 \%$ pure argon. 


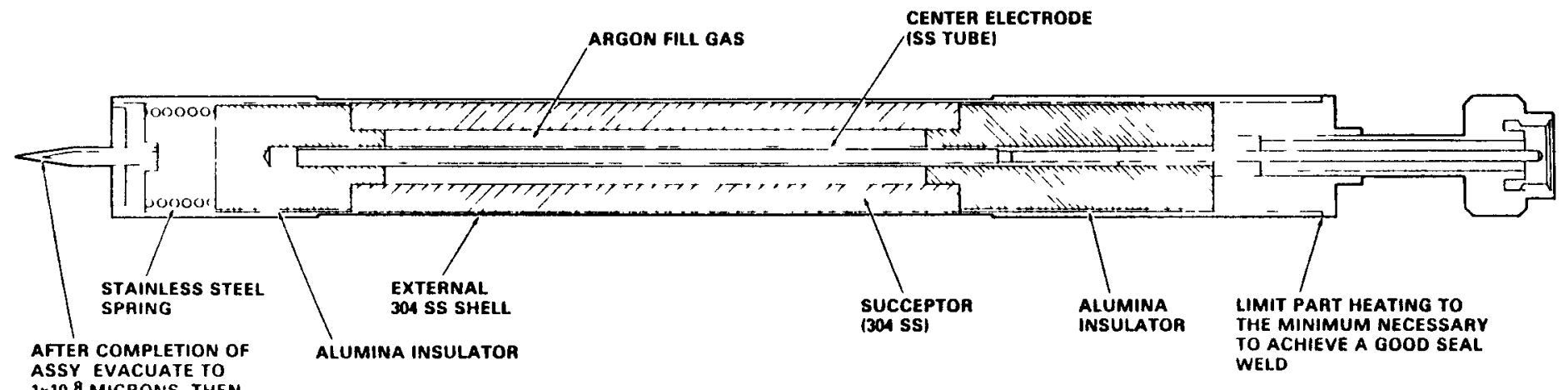

BACKFILL SEAL OFF

WELD TUBE

Figure 3.1. 304 stainless steel Bragg-Gray chamber typical assembly. 


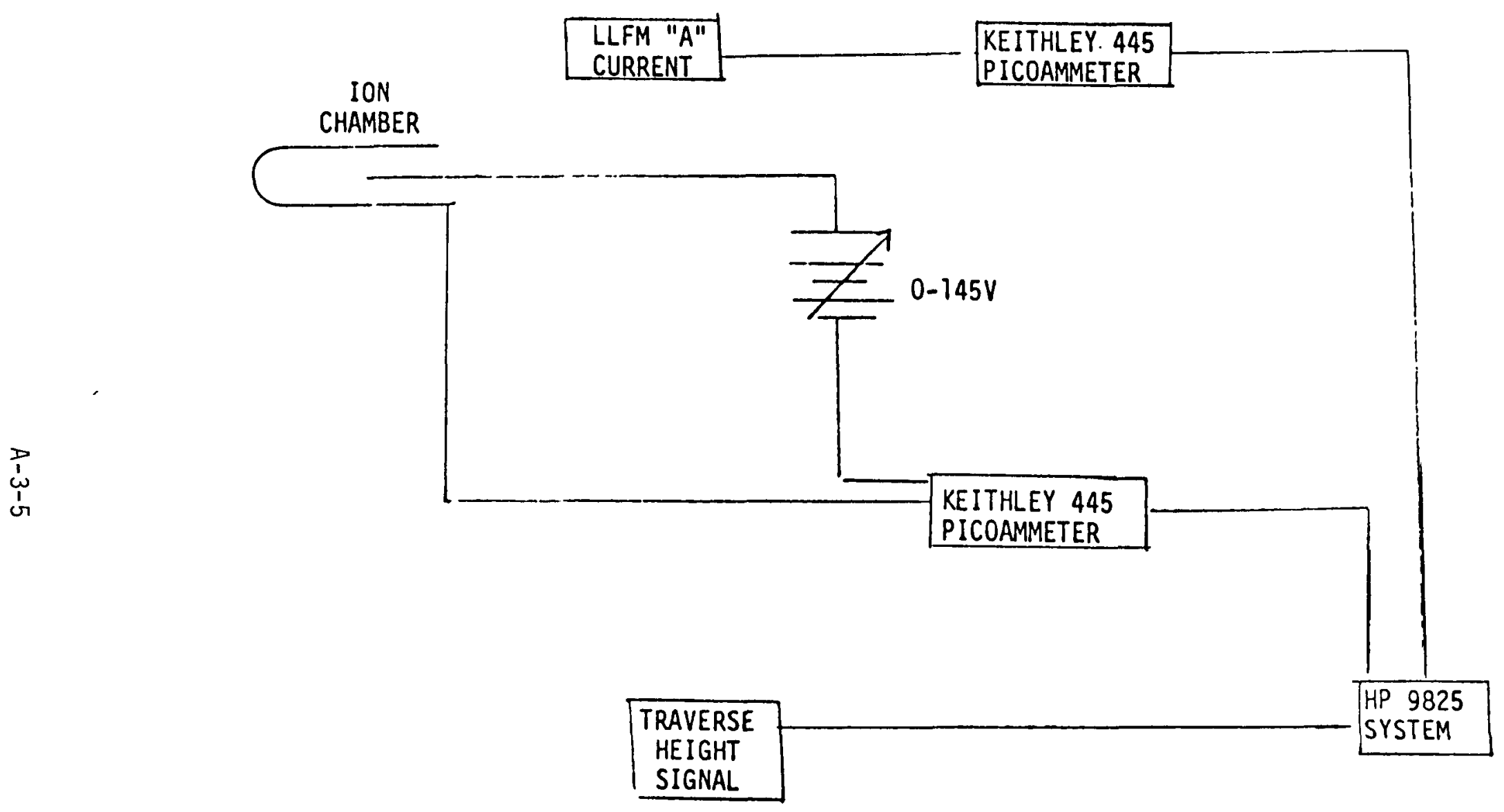

Figure 3.2. Electronics arrangement. 
each ion chamber and the LLFM are interrogated at preselected time intervals by the 9825 and the data recorded on magnetic tape.

The chambers were calibrated in the HEDL Cobalt Facility. This facility consists of $10^{5}$ curies of ${ }^{60} \mathrm{Co}$ shielded by $400 \mathrm{~cm}$ of water. Experimental tubes penetrate the water into the experimental region to permit insertion of experiments. The radiation field in the various experimental tubes has been measured by Pacific Northwest Laboratories and calibrations made for each experimental port in terms of $\mathrm{Rad} / \mathrm{hr}\left(\mathrm{H}_{2} \mathrm{O}\right)$. The response of each chamber was measured in these known fields and the sensitivity of each chamber measured. In these calibrations the interconnecting cables planned for the actual experiment were used. The Keithley 445 picoammeters to be used were employed and identified so that the identical combinations of chamber, cable and picoammeter could be used in the actual measurement to minimize calibration changes due to different electronics. The calibration factors for the chambers are given in Table 3.2 .

Table 3.2

\section{CALIBRATION FACTORS FOR IONIZATION CHAMBERS}

$\begin{array}{lcc}\text { Chamber } & \begin{array}{c}\text { Sensitivity } \\ {\left[\mathrm{amp} / \mathrm{Rad} / \mathrm{hr}\left(\mathrm{H}_{2} \mathrm{O}\right)\right]}\end{array} & \mu / \rho \\ \text { CK-2 } & 1.01 \times 10^{-13} & 0.0279 \\ \text { CK-3 } & 1.01 \times 10^{-13} & 0.0279 \\ \text { CK-4 } & 1.01 \times 10^{-13} & 0.0279 \\ \text { TK-1 } & 1.76 \times 10^{-13} & 0.0353 \\ \text { SK-1 } & 1.22 \times 10^{-13} & 0.0262\end{array}$

A Monte Carlo analysis of the Gamma Facility was made to investigate whether or not the chamber response to the ${ }^{6}{ }^{\circ} \mathrm{Co}$ gamma rays, modified by water and the steel in the facility, was an adequate representation of the calculated gamma spectrum of the FTR (as shown in Figure 1.2), or if a correction factor for the spectrum differences must be calculated. The results of the Monte Carlo calculation showed that the modified spectrum was indeed adequate for the experiment. 


\subsection{Proposed Experiment}

As indicated, the tungsten and steel wall ion chambers are small enough to utilize the IRT Traversing Mechanism, which will permit an axial traverse from below the core up to the fission gas plenum region above the core, covering a distance of approximately seven feet. The reactor power level will be held constant at about $10 \mathrm{~kW}$ during the traverse. As indicated in Figure 3.2, the current data as a function of position will be recorded together with elevation information for subsequent interpretation of the measurements.

Because of the size of the graphite ion chamber, it will not be possible to use the traversing mechanism. Axial information will be obtained by locating three different graphite ion chambers, with one at the core midplane, one centered 38 centimeters below the core midplane, which is still within the core but near the lower reflector, and one centered in the upper axial reflector at an elevation of 53 centimeters above the core midplane. Data will be obtained on all three of the graphite chambers while the reactor is being brought up to a power level of approximately $10 \mathrm{~kW}$. With the reactor held $a t$ this steady power level, data will be recorded to measure the growth of activation products. Finally, the reactor will be shut down and the decay of the activation products monitored for a reasonable length of time.

Both the traversing ion chambers and the static chambers will be irradiated while surrounded by a steel spectral plug. The steel spectral plug will provide a common global field that will simplify and standardize the calculations for interpretation of the measurements. The perturbation introduced by the chambers will not be included in the global calculations, but can be applied on an individual basis as necessary.

\subsection{Expected Results}

The calculated axial distribution is shown in Figure 2-1, and it is anticipated that the traversing chambers will generate data consistent with this shape. 
Because of the different wall materials, it is anticipated that the core midplane dose rates will have the ratio 0.8:1.0:125, for carbon:steel:tungsten, respectively. Significant deviations in the calculated ratio will indicate a shortcoming in the calculational technique. When the results of the measurements are taken together with all other results, the gamma ray environment in the reactor should be established with a high degree of accuracy.

\subsection{Acknowledgement}

The ion chambers to be used in these measurements were designed by Dr. Bruce Kaiser of the Instrument Development group at HEDL, who was also responsible for devising the electronic system and calibration methods.

\subsection{Reference}

1. Radiation Dosimetry, Volume 1 Fundamentals, Edited by F. H. Attix, W. C. Roesch, Academic Press, New York (1968). 


\subsection{IRT ADIABATIC CALORIMETER}

\subsection{Introduction}

The energy deposition rate in a material may be inferred from an ionization chamber as indicated in the previous section. A calorimeter provides a method of measuring the energy deposition rate directly in a material, and they are commonly used for that purpose. [1], [4] It is desired to make a calorimeteric measurement with in the In-Reactor Thimble at the same position and in the same environment that several other active and passive gamma ray measurements are to be made. Because of the reactor power level limitation associated with the use of the IRT, a special adiabatic calorimeter was designed, constructed and tested which had sufficient sensitivity to obtain data to these flux levels. Although it will provide a direct measurement of energy deposition, it cannot be assured that no bias will exist; therefore, the calorimetric results will be used together with the other measurements to establish the energy deposition rate and its uncertainty.

\subsection{Basis For Design}

The basic calorimeter equation is:

$$
\dot{q}=C \frac{d T}{d t}+K\left(T-T_{s}\right)
$$

where, $\dot{q}$ is the energy deposition rate,

$C$ is the sensor specific heat,

$T$ is the sensor temperature,

$T_{S}$ is the temperature of the surroundings,

$K$ is the energy loss coefficient of the calorimeter system.

If the energy loss term can be made negligible, that is, no energy loss or gain from the surroundings, the calorimeter is adiabatic and the measurement of $\mathrm{dT} / \mathrm{dt}$, the rate of change of temperature of the sensor with respect to 
time, gives the energy deposition rate. At a reactor power level of $500 \mathrm{~kW}$, the calculated energy deposition rate is approximately $5 \mathrm{~mW} / \mathrm{gm}$ for stainless steel located within the IRT. For a specific heat of 0.12 , the predicted temperature rise is $0.5^{\circ} \mathrm{C} /$ minute. This is a more than adequate rate to provide satisfactory data.

\subsection{Design and Construction of Calorimeter}

The design of the IRT calorimeter is shown in Figure 4.1. The stainless steel sensor is a right circular cylinder 3 inches long and .960-inch in diameter, made of 3.6 stainless steel polished to a fine finish to control and minimize radioactive losses. To make the calorimeter adiabatic, the sensor is surrounded by a heat shield. The sensor is supported within the heat shield on nylon threads, to minimize conductive losses, and the heat shield, made of goldplated copper to minimize radiation to the sensor at operating temperatures, is insulated from the calorimeter case. The heat shield has a nichrome wire heater wrapped around it to allow heating the shield to permit it to track the temperature of the sensor. In this way, heat transfer between the shield and sensor is minimized and the sensor isolated from the case, ensuring adiabaticity. Resistance temperature detectors (RTD's) are embedded in both the heat shield and the sensor to monitor temperature. In addition, there is a calibration heater within the sensor for calibration purposes. The entire assembly is evacuated to minimize heat transverse by conduction or convection.

An engineering model of the calorimeter was constructed to verify the operation of the heat shield control system and to qualify construction methods. This model was tested in a gamma ray field of approximately one million R/hr, generated by approximately one hundred thousand curies of cobalt. This gamma ray field is comparable to that anticipated in the FTR-IRT at a power level of $100 \mathrm{~kW}$. These experiments confirmed the operational characteristics of the calorimeter by yielding a heating rate of approximately $0.1^{\circ} \mathrm{C} /$ minute as predicted. 


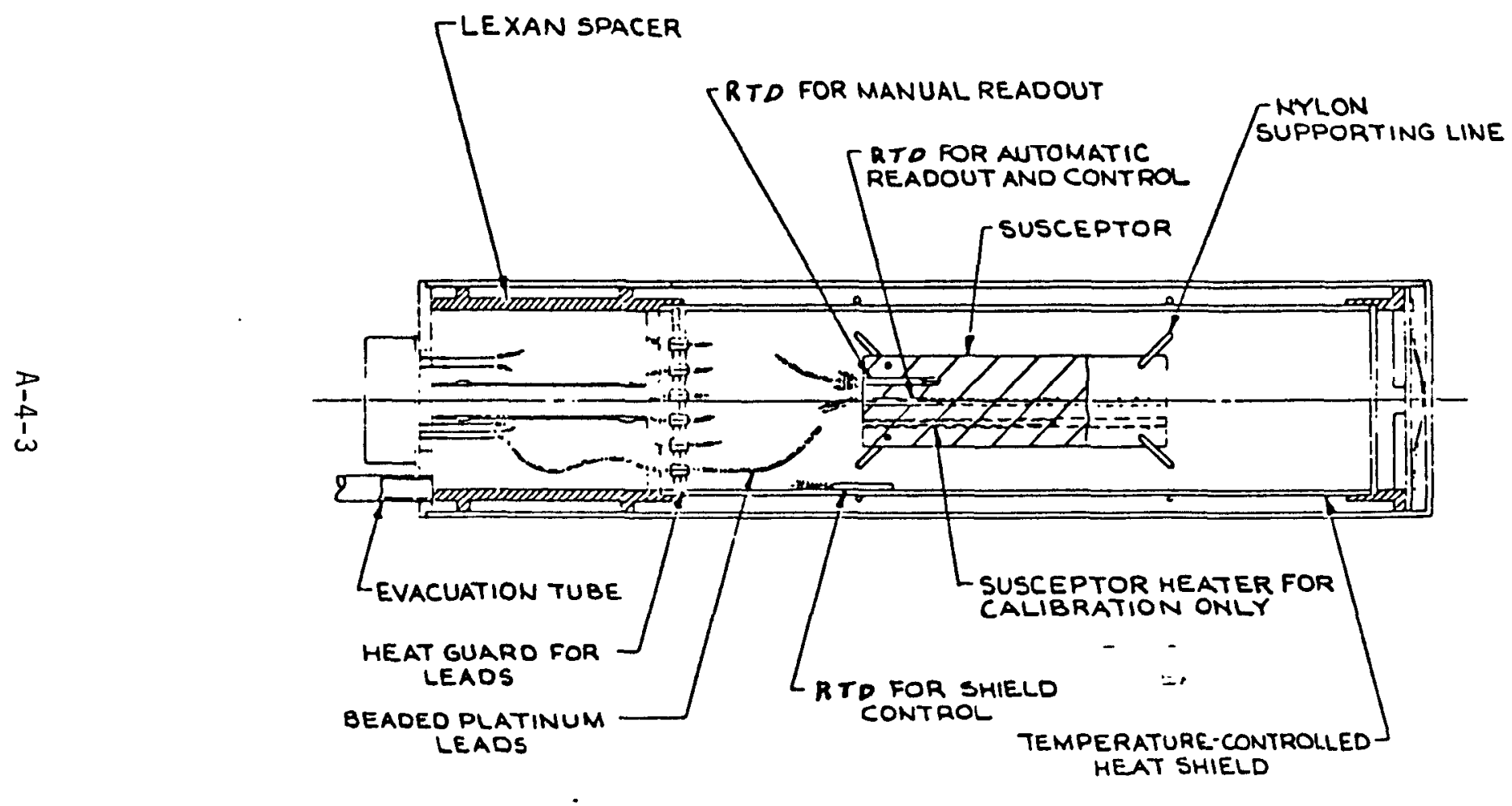

Figure 4.1. Calorimeter for the In-Reactor Thimble. 


\subsection{Calibration and Operation of the Calorimeter}

In order to measure the energy deposition rate, the specific heat of the asbuilt sensor must be known. Also, the size of the energy loss coefficient, $K$, must be determined so that a correction for losses may be made if necessary. The techniques of Reference 4 were used to perform the calibrations. The results of this calibration are as follows:

$$
\begin{aligned}
& \mathrm{C}=0.1266 \text { joules } / \mathrm{gm} /{ }^{\circ} \mathrm{C} \\
& \mathrm{K}=1.20 \times 10^{-2} \mathrm{~mW} / \mathrm{gm} /{ }^{\circ} \mathrm{C}
\end{aligned}
$$

In addition, other tests were made to verify the correct operation of the system. Figure 4.2 shows one of these tests. In this test, the calibration heater supplied heat to the sensor at a rate corresponding to approximately $5 \mathrm{~mW} / \mathrm{gm}$. The response of the shield temperature controller was studied, and it can be seen that the temperature of the shield is maintained within $0.2^{\circ} \mathrm{C}$. At $55^{\circ} \mathrm{C}$, the shield control was changed from automatic to manual to ensure that, if the automatic system failed, the temperature could be controlled manually accurately enough to continue the experiment. At approximately $60^{\circ} \mathrm{C}$, the heater was turned off and the cooldown of the system investigated.

Figure 4.3 shows the instrumentation arrangement for the experiment. The temperature recorder for the thermocouple in the gaseous nitrogen $\left(\mathrm{GN}_{2}\right)$ is part of the IRT instrumentation to record the temperatures in the IRT. RTD's $A$ and $C$ read out the sensor temperatures, and RTD $B$ reads out the shield temperature. The temperatures of RTD's $A, B$ and $C$ are recorded by the Hewlett-Packard 9825 Data Logger, which controls the experiment. Programs were written for this computer to control data taking for the calibration measurements as well as the actual experiment.

\subsection{Proposed Experiment}

In the proposed experiment, the calorimeter will be placed in the IRT and located at the midplane elevation of the core with the reactor shut down. 
Aesy \#3 trial run

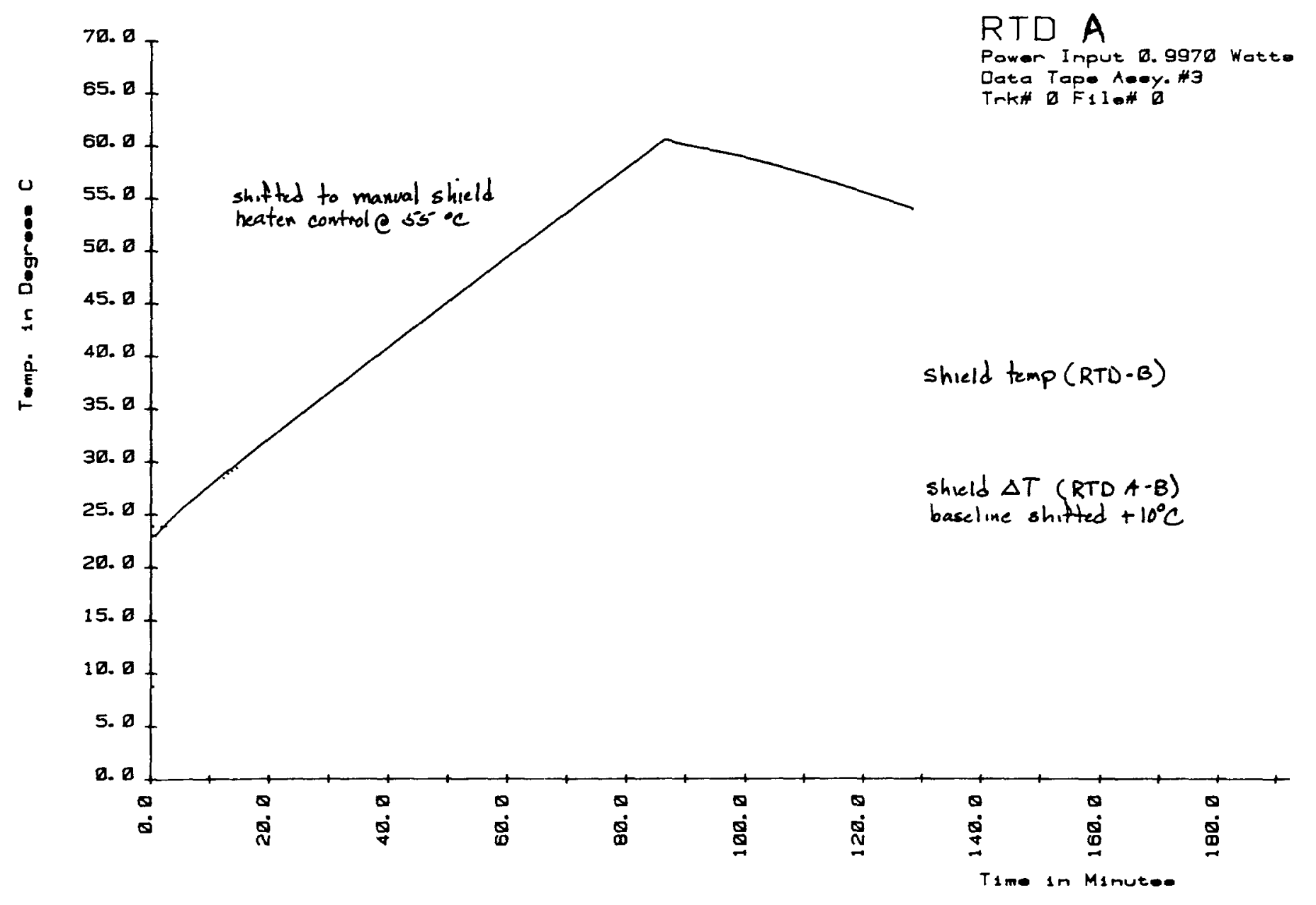

FIGURE 4.2 


\section{Block Diagram}



Note: All electronics for the calorimeter system are expected to be on the operating deck.

Figure 4.3. Schematic representation of calorimeter and temperature measurement instrumentation. 
Sufficient time will be taken to establish an equilibrium temperature in the calorimeter and to assure that the entire system is operating satisfactorily. The reactor will then be taken to a power level of approximately $500 \mathrm{~kW}$ as rapidly as possible, and this power will be held as constant as possible. The power level data will be recorded on the 9825 for later correction if the reactor power varies significantly. The rate of rise of the sensor temperature will be monitored, and periodic calculations of the energy deposition rate will be made by the 9825 computer to verify correct system operation. The temperatures of RTD's A, B and C will be recorded and 211 measurements will be recorded on magnetic tape for subsequent retrieval when desired. The reactor will be scrammed or shut down as quickly as possible when sufficient data have been obtained to define the rate of rise accurately and prior to the time the temperature will become excessive for the nylon structural members of the calorimeter. The calorimeter will then be allowed to cool down to ambient temperature, after which time a second data run will be made. Preliminary evaluation of the data will be made at that time to ensure that adequate and consistent data have been taken and to determine whether or not any additional measurements need to be taken.

\subsection{Expected Results}

Based on the results of energy deposition calculations, it is anticipated that a rate of rise of about $0.5^{\circ} \mathrm{C} /$ minute will be achieved in the sensor with the reactor operating at a constant power level of $500 \mathrm{~kW}$. If all systems function properly during the test, preliminary results will be available throughout the proposed runs. Subsequently, more refined evaluation of the data will be required to include any necessary corrections, including power level normalization.

\subsection{Acknowledgements}

Design and fabrication of the adiabatic calorimeter was carried out under the direction of M. R. Wood. Calibration of the system and development of the instrument system was carried out by D. L. Tibbals. 


\subsection{References}

1. H. J. Leyers, "Die Neutronen- und Gamma-Aufheizung in Experimentierkanälen des Reaktors FRJ2," Nukleonik, ㅍ, 300-309 (1965).

2. A. R. Anderson and R. J. Waite, "A Calorimeter for Measuring Energy Absorption from Pile Radiation," Journal of Scientific Instruments, 33, 46-51 (1956).

3. J. M. Otter, T. H. Springer and C. A. Guderjahn, Heating of Neutron Absorbers in LMFBR Critical Assemblies, N707TR220001, Atomics International Division, Canoga Park, CA (June 1976).

4. Karsten Haack, Nuclear Heat Dose Rate Separation by Calculation and Measurement, Ris $\varnothing$ Report No. 119, Danish Atomic Energy Commission Research Establishment Ris $\varnothing$, DK-4000 Roskilde, Denmark (March 1972). 


\subsection{VOTA IONIZATION CHAMBERS}

\subsection{Introduction}

The measurements described in Sections 1 through 4 are all to be made in the In-Reactor Thimble, which is to be located in core position 3202, adjacent to the center of the core, at reactor power levels up to about $500 \mathrm{~kW}$. The Vibration Open Test Assembly (VOTA) will be located in core position 1610, which is adjacent to the reflector. The VOTA is to remain in the reactor during the first few cycles of operation at power, and thus provides a vehicle in which long-term gamma ray measurements are possible.

A second major difference between the IRT and the VOTA is the environment. The IRT is a thimble that provides a dry hole in which measurements can be made. The instruments in the VOTA are in direct contact with the primary reactor sodium and must be designed to operate at full reactor power (400 $\mathrm{mW}$ ) for long periods of time. The VOTA sensors should have as wide a dynamic range as possible, but should be designed to assure operation at $400 \mathrm{~mW}$. In addition to measuring the intensity of the gamma ray field during operation, the ion chambers should be able to follow the decay of the gamma ray field following shutdown of the reactor. Both the steady-state and the transient information will be of value in refining and improving analytical techniques.

\subsection{Design and Construction of VOTA Ion Chambers}

Ionization chambers were obtained from two different commercial vendors for operation in the VOTA. Although the chambers are of similar design, the intent was to provide diversity as well as redundancy to assure that reliable data could be obtained. Tables 5.1 and 5.2 give the basic dimensions of the chambers. For proprietary reasons, drawings of the chambers are not shown. There are four dionization chambers mounted in the VOTA, as illustrated in Figure 5.1. With the VOTA located at position 1610, adjacent to the reflector, 
TABLE 5.1

REUTER STOKES DETECTOR SPECIFICATIONS

$\begin{array}{ll}\text { Material } & -316 \text { SS } \\ \text { Insulator Material } & - \text { Alumina } \\ \text { Fill Gas } & - \text { Ar (Research Purity) } \\ \text { Detector Length }(\text { in }) & -2.45 \pm .1(2.5-2.548)^{\mathrm{a}} \\ \text { Sensitive Length }(\text { in }) & -1.00 \\ \text { Fill Tube Length (in) } & -5 / 8 \max (.41-.49)^{\mathrm{a}} \\ \text { Detector Diameter (in) } & -.25 \max (.245-.247)^{\mathrm{a}}\end{array}$

$a_{\text {measurements made by vendor }}$ 
TABLE 5.2

WESTINGHOUSE DETECTOR SPECIFICATION

$\begin{array}{ll}\text { Material } & -321 \text { SS } \\ \text { Insulator Material } & - \text { Alumina } \\ \text { Fill Gas } & -\operatorname{Ar}(99.999 \%) \\ \text { Detector Length }(\text { in) } & -2.13 \pm .12 \\ \text { Sensitive Length }(\text { in) } & -1.00 \\ \text { Detector Diameter } & -0.187 \pm .010 \\ \text { Cable Sheath } & -321 \mathrm{SS} \\ \text { Cable Insulator } & - \text { Alumina } \\ \text { Cable 0.D. } & -0.125 \pm .002 \\ \text { Total Length } & -40 ' \min .\end{array}$

WESTINGHOUSE DETECTOR MEASUREMENTS ${ }^{a}$

\begin{tabular}{cccccc} 
S/N & $\begin{array}{c}\text { Cable } \\
\text { S/N }\end{array}$ & $\begin{array}{c}\text { Detector } \\
\text { Length (in) }\end{array}$ & $\begin{array}{c}\text { Detector } \\
\text { 0.D. (in) }\end{array}$ & $\begin{array}{c}\text { Total } \\
\text { Length }\end{array}$ & $\begin{array}{c}\text { Cable } \\
\text { OD (in) }\end{array}$ \\
\hline 775201 & $77359 \mathrm{~A}$ & 2.13 & .189 & $41^{\prime} 7^{\prime \prime}$ & .126 \\
775202 & $77359 \mathrm{~B}$ & 2.12 & .188 & $41^{\prime} 7^{\prime \prime}$ & .126 \\
775203 & $77359 \mathrm{C}$ & 2.12 & .188 & $41^{\prime} 7^{\prime \prime}$ & .126 \\
775204 & $773510 \mathrm{C}$ & 2.13 & .189 & $41^{\prime} 6^{\prime \prime}$ & .126
\end{tabular}




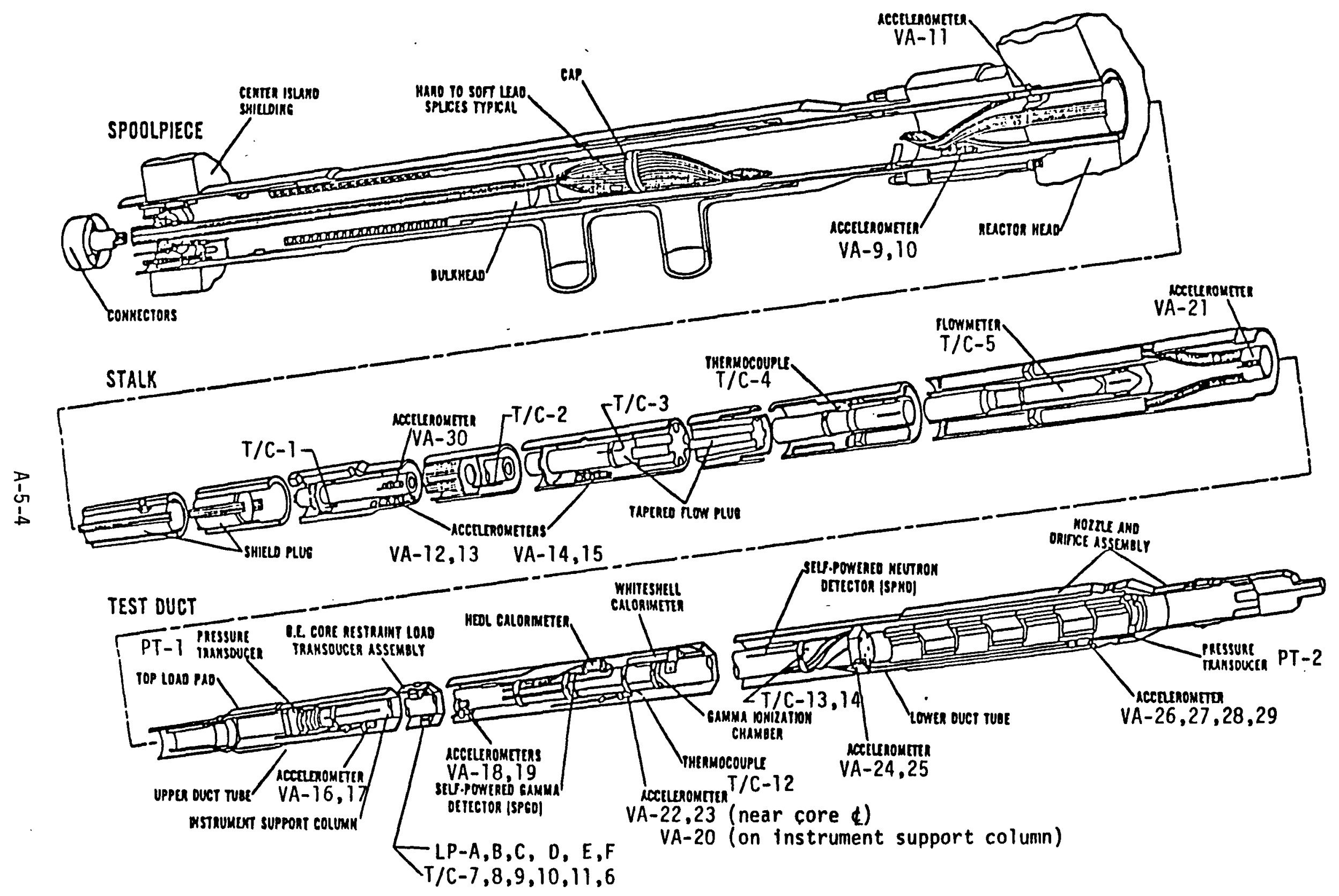

Figure 5.1. Vibration Open Test Assembly (VOTA). 
a significant gamma ray flux gradient is expected to exist. Therefore, two of the ion chambers are paired up to provide a measurement of this radial gradient. In addition, axial information will also be achieved for comparisons to 3 -dimensional calculations of the gamma ray field.

\subsection{Calibration and Instrumentation}

Because of the operating environment, an extensive testing program was undertaken. First, the integrity of the seal connecting the detector to the hard line triax cable was tested, and then the operation of the entire detectorcable system at high temperatures was evaluated. The detector and 8 inches of cable were placed in an oven and the cable resistance and capacitance measured with a megohm bridge and an impedence bridge as a function of temperature from $26^{\circ} \mathrm{C}$ to $508^{\circ} \mathrm{C}$. At the conclusion of this test, the detectors were placed in an eight foot long furnace which was lowered into one of the test ports in the HEDL gamma facility. The gamma dose rate at the detector was $4.88 \times 10^{5} \mathrm{R} / \mathrm{hr}$. The experimental arrangement is shown in Figure 5.2 . With 100 volts applied, the current was recorded as the temperature was raised. At the point at which the current indicated extensive temperature induced insulation resistance reduction, the test was terminated and the detector allowed to c0ol. Detector-cable systems whose temperature thresholds were too low were deleted from the work.

The ion chambers were calibrated using two separate ${ }^{60} \mathrm{Co}$ facilities. The primary calibration was performed in the HEDL water shielded cobalt facility described earlier, while the secondary calibration was done in the Pacific Northwest Laboratory (PNL) open air cobalt facility.

Figures 5.3 and 5.4 show the experimental arrangements and the equipment used in the calibration program. Current versus voltage curves for a fixed source were first made to ensure that the detectors were operated at an optimum point on the "plateau" of the ionization current versus voltage curve. Based on these data, an operating voltage of 100 volts was used for each detector. Next, 


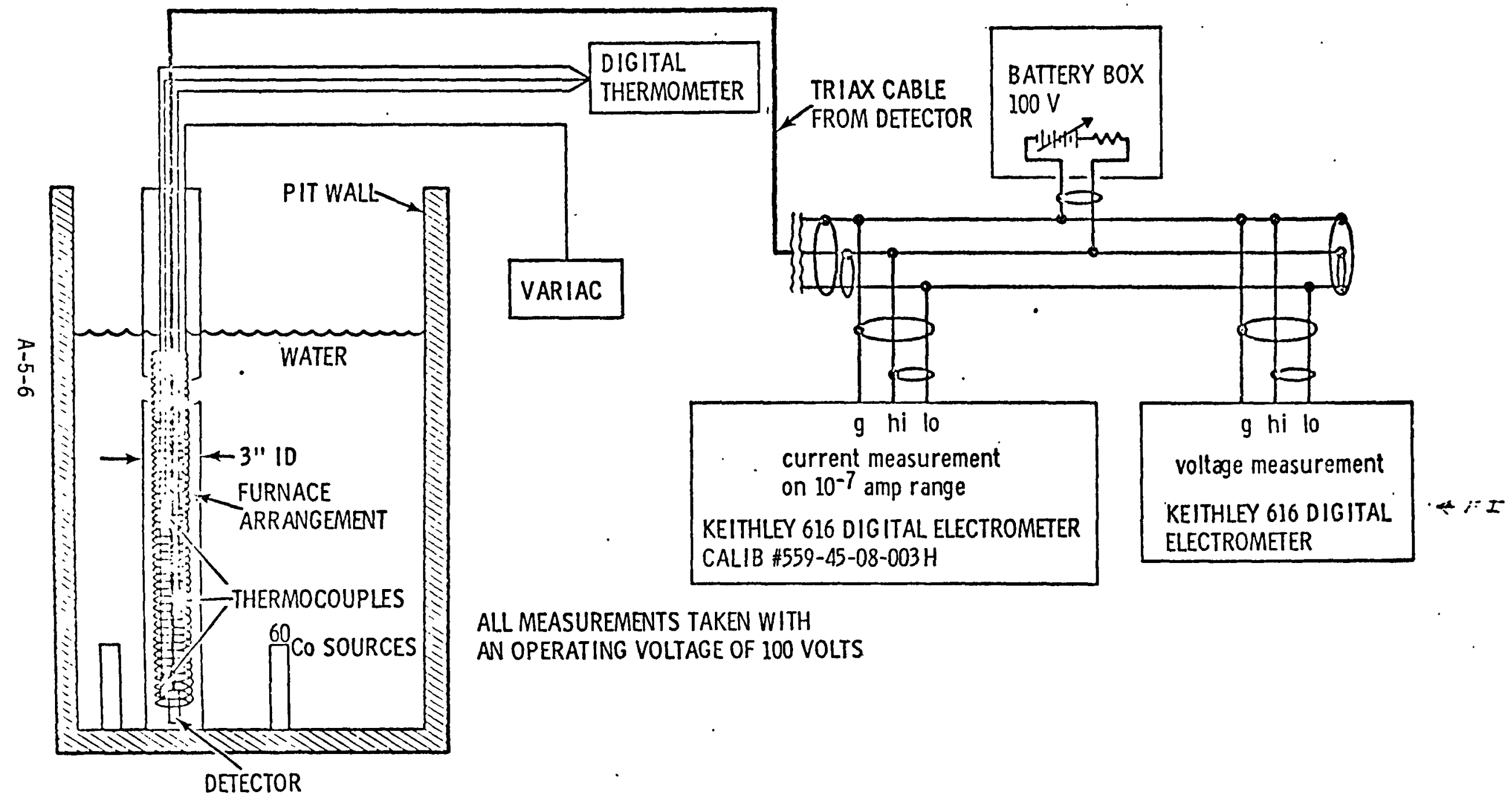

Figure 5.2. Data Acquisition for In Situ Gamma Ionization Chamber Tests. 


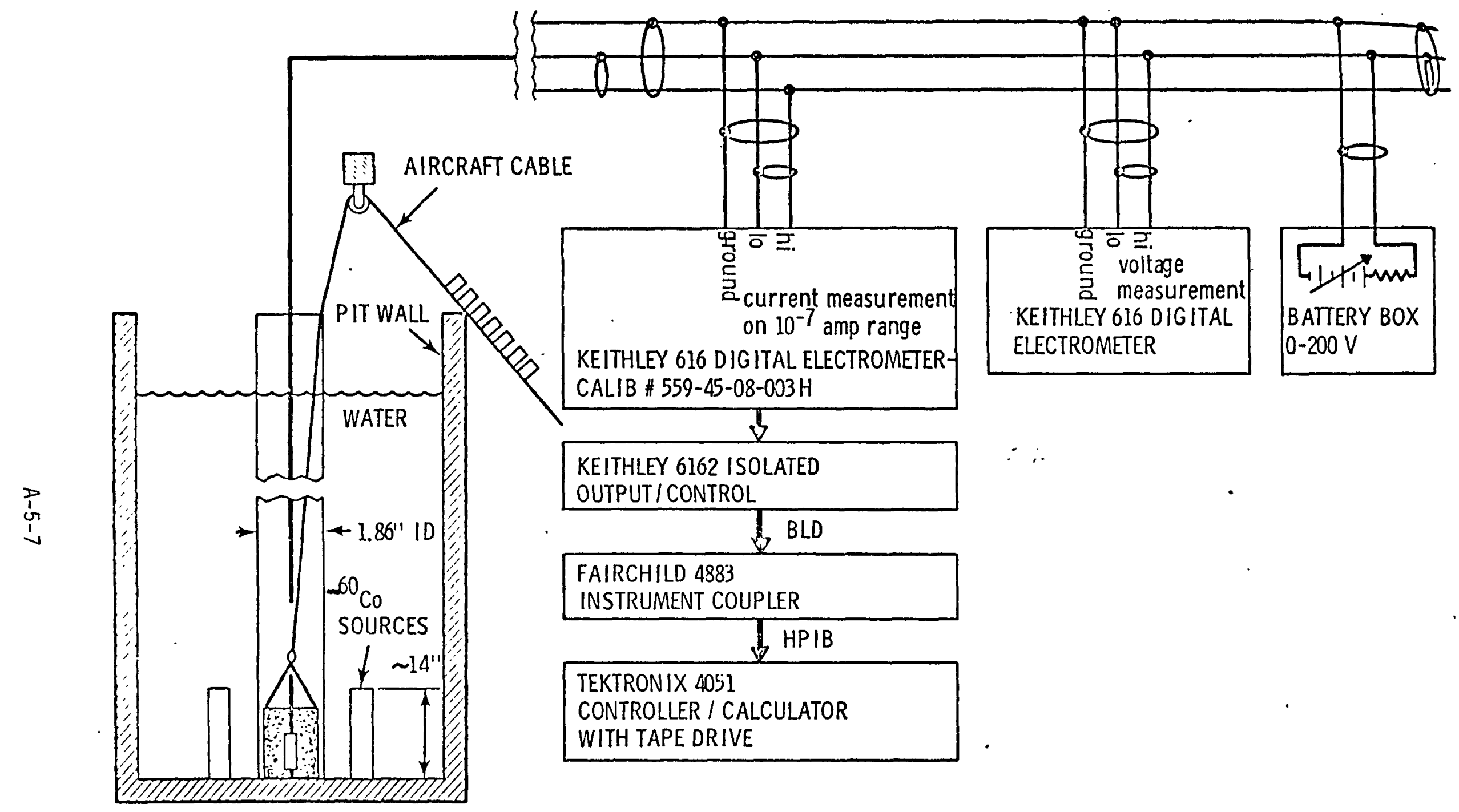

FIGURE 5.3. Block diagram of HEDL ${ }^{60}$ Co Facility and associated data acquisition equipment. 


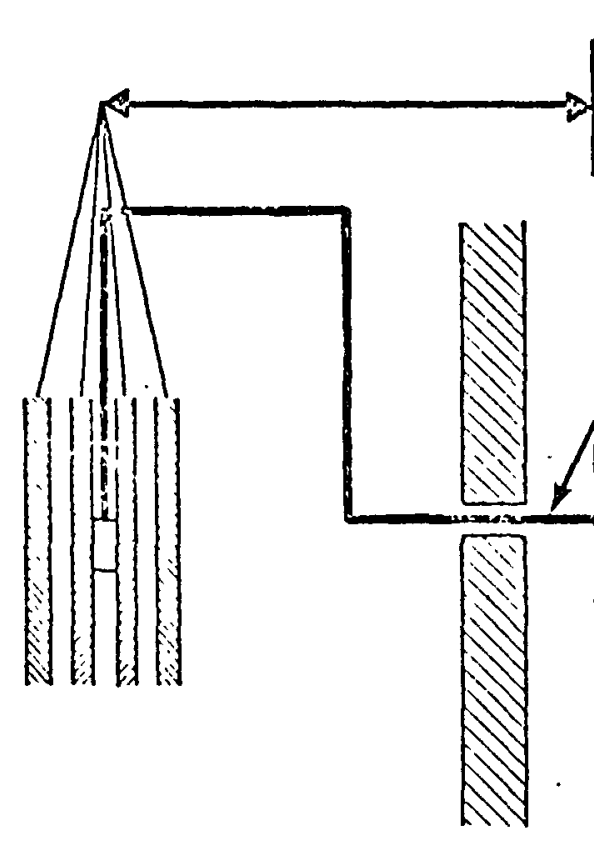

ALL MEASUREMENTS TAKEN WITH AN OPERATING VOLTAGE OF 100 VOLTS. AXIAL POSITION = FOR ALL
PNEUMATIC CONTROL OF ${ }^{60}$ CO TUBES

TRIAX CABLE FROM DETECTOR
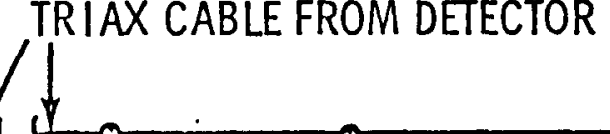
on $10^{-7}$ amp range KEITHLEY 616 DIGITAL ELECTROMETERCALIB \#559-45-08-003H

BATTERY BOX $100 \mathrm{~V}$
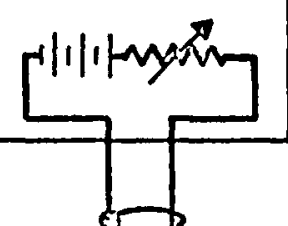

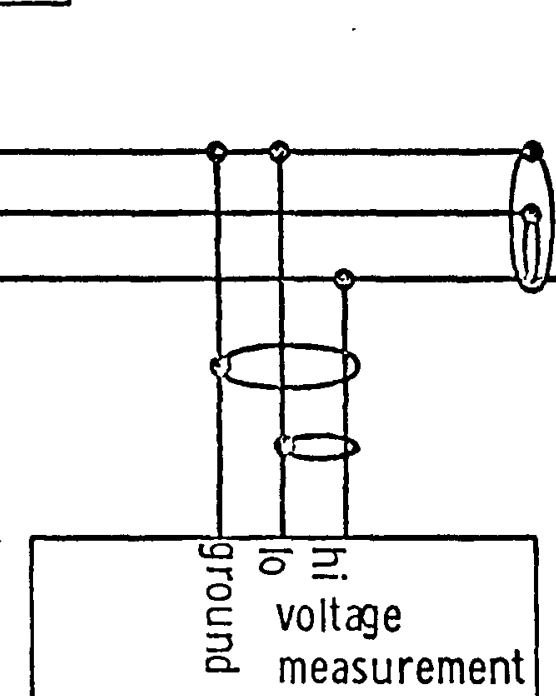
KEITHLEY 616 DIGITAL ELECTROMETER

FIGURE 5.4. Block diagram of BNW Open Air ${ }^{60}$ Co Facility and associated data acquisition equipment. 
data were taken to determine the sensitivities of the various detectors. The dose rate was varied by changing the elevation of the ion chamber in the HEDL facility, and by pneumatically changing the combination of Co sources in the PNL facility. The data were collected and analyzed to determine the sensitivity of the various ion chambers in $\mathrm{Rad} / \mathrm{amp} / \mathrm{hr}$.

\subsection{Proposed Experiment}

The VOTA was loaded into the reactor prior to the time of the initial fuel loading. The ionization chambers were immersed in sodium at temperatures between $400^{\circ} \mathrm{F}$ and $800^{\circ} \mathrm{F}$ for several months prior to the startup and operation of the reactor. This waiting time will introduce uncertainty into the results because of the possible change in calibration that could occur. Data from the ionization chambers will be recorded during each power ascent, intermittently during steady-state power operation, and during power descent for as long as the VOTA is in the reactor or for as long as the chambers continue to operate satisfactorily.

\subsection{Expected Results}

The gamma ray dose rate at the midplane elevation of the row 6 VOTA is calculated to be $2 \times 10^{9} \mathrm{R} / \mathrm{hr}$. The ion chamber results are expected to provide data that will either confirm these calculations or that will provide a basis for upgrading the analytical technique. Additionally, the diffusion theory calculations provide an estimate of the axial distribution, which will also be established by the VOTA ion chamber readings.

Additional information that can be obtained from the VOTA ionization chambers is a measure of the decay field as a function of time. Although the total gamma ray energy deposition rate during equilibrium operation of the reactor is calculated to be about $14 \%$ of the total energy, only about three-fourths of the gamma ray energy is prompt with about one-fourth being delayed and associated with the beta decay of fission products and radioactivants. It 
should be possible to establish more precisely the relationship between the prompt and delayed components of the gamma ray field in the reactor, and to compare the time-dependent decay rate with predicted values. If measurements of sufficient precision are obtained over several different operating cycles, a wealth of information should be available for subsequent analysis.

\subsection{Acknowledgements}

The authors would like to acknowledge the assistance, cooperation and technical input provided Dr. Bruce Kaiser in calibrating these ionization chambers and the electronic equipment. We would also like to acknowledge Pacific Northwest Laboratory for the use of their cobalt facility. 


\subsection{VOTA SELF-POWERED GAMMA RAY DETECTOR}

\subsection{Introduction}

Self-powered gamma ray detectors using platinum wires are similar to ion chambers in operation, but have inherent differences that provide an additional diversity that might reveal biases and ultimately permit the attainment of higher accuracy than might otherwise be possible. A selfpowered gamma ray detector has a platinum anode surrounded by MgO insulation and a stainless steel cathode. Gamma rays interacting with the platinum eject electrons as a result of Compton scattering and the photoelectric effect. The ejected electrons travel to the stainless steel case, creating a potential difference between the central anode and the case. This same self-powered effect occurs in the cable connecting the detector to the readout instrumentation for that portion of the cable which is in a radiation field, hence a second lead, called the compensation lead, is included in the cable, and this signal is subtracted from the detector signal to compensate for the cable self-powered effect. These commercially available detectors have been applied previously in light water reactors and in the EBR-II program; ${ }^{[1]}$ hence, it was deemed desirable to utilize them in the FTR measurements.

\subsection{Design and Construction of Detector}

Pertinent design and construction features of the platinum self-powered gamma ray detectors are shown in Figure 6.1 . The 21 " long $(508 \mathrm{~mm})$ platinum emitters are encased in a 0.061-inch outside diameter steel sheath. The compensation lead can be seen to terminate near the end of the platinum emitter where the lead cable is jointed to the collector case. As indicated, the entire assembly is annealed at $1800^{\circ} \mathrm{F}$, which is well below the planned operating temperature in the Fast Test Reactor. Because of the proprietary nature of the sensors, additional details are not available. 


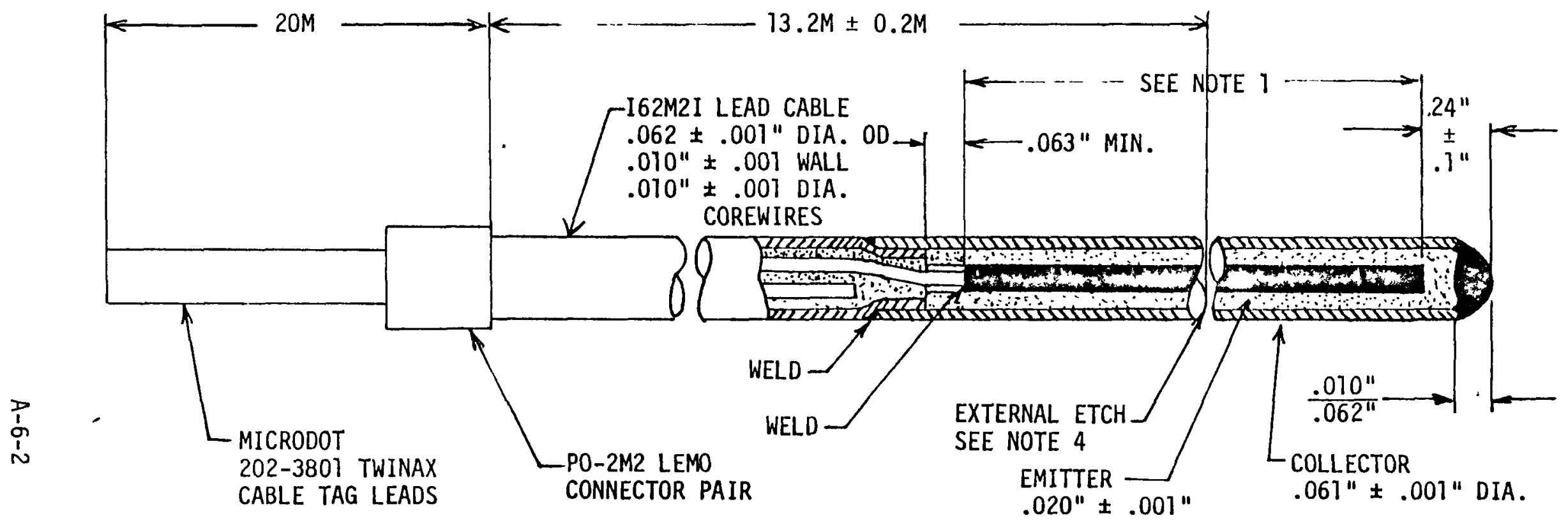

NOTES:

1. GAMMA DETECTORS USE $508 \mathrm{MM} \pm 5.00 \mathrm{MM}$ LONG PLATINUM EMITTER.

2. FINISHED DETECTOR TO BE ANNEALED AT $1800^{\circ} \mathrm{F}$.

FIGURE 6.1. Vendor Supplied As-Built Drawing For The Platinum Detectors . 


\subsection{Calibration and Instrument System}

The response of the platinum self-powered detectors was measured in the HEDL cobalt gamma ray facility. This facility contains on the order of a hundred thousand curies of ${ }^{60} \mathrm{Co}$ which can be arranged around thimbles to provide fields of various strengths. Figure 6.2 illustrates the general arrangement of the sensor, sources, and readout instrumentation. For these measurements, the 20 "long sensors were coiled to approximately a $3^{\prime \prime}$ diameter coil. This placed the entire length of the sensor in about the same radiation field and el iminated the problems associated with correcting for gradients. As designed, the signal from the emitter is positive because the net flow of electrons in the detector is away from the emitter lead. The sensitivity of the platinum self-powered detector was determined to be $4.85 \times 10^{-16}$ amperes per $\mathrm{R} / \mathrm{hr}$.

\subsection{Proposed Experiment}

Two self-powered gamma ray detectors are installed in the VOTA, with one being 5 " above the core midplane elevation and the other $5^{\prime \prime}$ below. Because of their length, they are wrapped around the center duct of the VOTA, as illustrated in Figure 5.1. By coiling the sensitive region at a given elevation, the measured gamma ray field will have no axial dependence; however, the reading will obviously be averaged over the radial gradient that will exist in the VOTA location at the core reflector interface.

As in the case of the ionization chambers, current data from the self-powered gamma ray detectors will be taken during each power ascent and descent of the reactor as well as intermittently during steady-state operation. In addition, platinum self-powered detectors have good frequency response and are expected to be able to follow fluctuations in the gamma ray field at rates approximating $100 \mathrm{~Hz}$. A primary source of gamma rays in the reactor core will be from fission; hence, the gamma ray noise should be related to the neutron noise and one should be able to deduce the same information from the gamma ray noise as from neutron noise. Ion chambers and other standard gamma ray monitors do not 


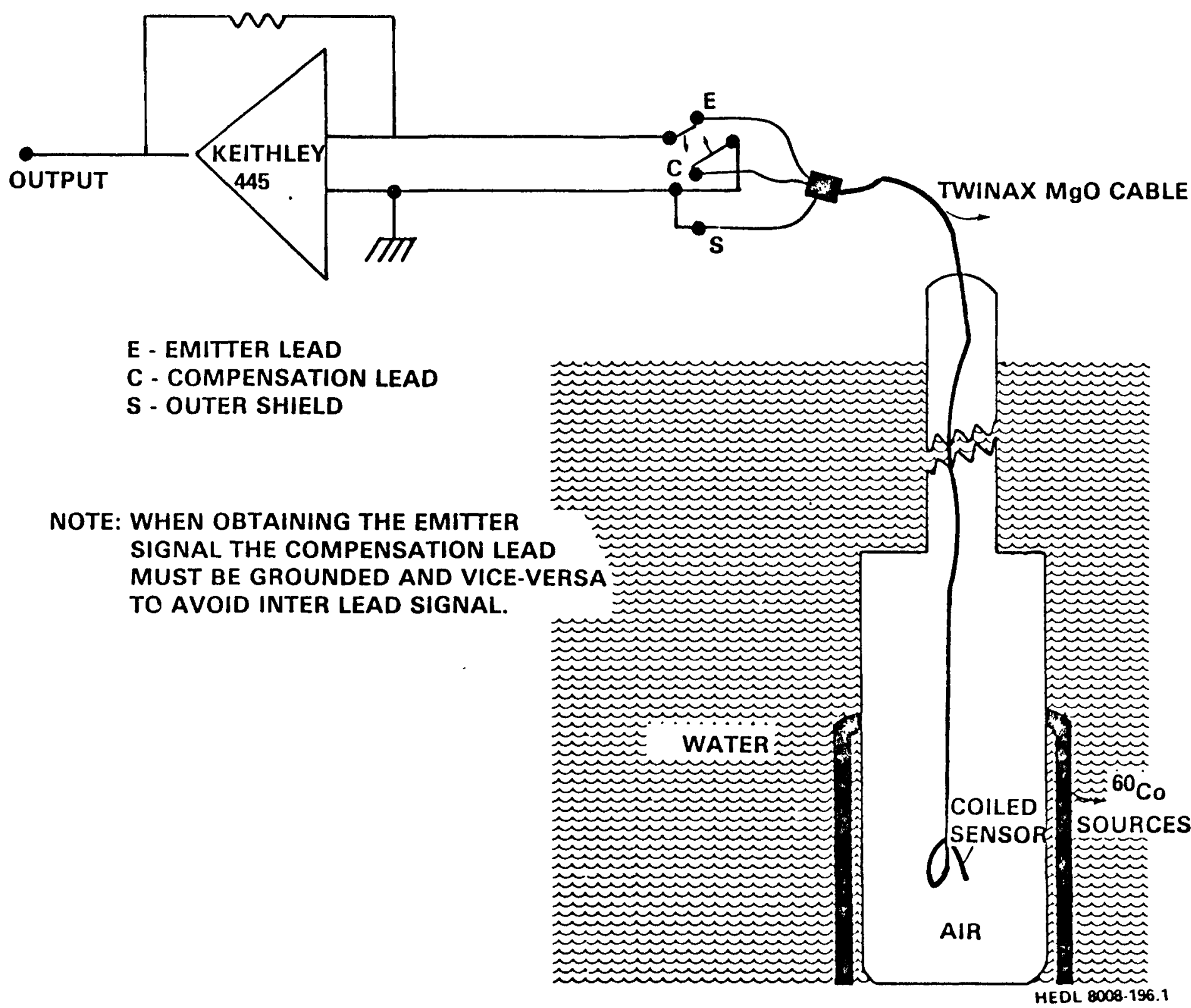

FIGURE 6.2. Gamma Measurement Block Diagram. 
have the frequency response required for such measurements, and the platinum self-powered detector provides a unique opportunity for applying this technique. During steady-state operation of the reactor, the self-powered gamma ray detector signal will be used for noise analysis to develop this technique.

\subsection{Expected Results}

The calculated gamma ray dose rate at the midplane elevation of the VOTA is $2 \times 10^{9} \mathrm{R} / \mathrm{hr}$. For the measured sensitivity of $4.85 \times 10^{-16}$ amps per $\mathrm{R} / \mathrm{hr}$, the self-powered detectors should give a current reading of about 0.9 microamps when the reactor is at full power. Because of the position of the control rods, the lower detector should give a slightly higher reading than the upper detector. Comparison of the dose rate readings from the self-powered detectors and the ionization chambers will require consideration of axial and radial gradients. Any significant difference between the dose rate measurements of the various types of detectors that is outside the expected accuracy will indicate that a potential bias exists. All of the gamma ray measurements will be used to provide the most accurate value that can be realized.

\subsection{Acknowledgements}

The authors acknowledge the assistance provided by Dr. Bruce Kaiser in calibrating the self-powered gamma ray detectors and establishing their operational characteristics.

\subsection{Reference}

1. C. C. Price and J. R. Karvinen, "Performance Testing of Self-Powered Detectors in EBR-II Instrumented Subassemblies XX01, XX03, and XX04," ANL-8030, November 1973. 


\subsection{VOTA WHITSHELL CALORIMETERS}

\subsection{Introduction}

The VOTA provides a unique opportunity to measure gamma ray heating directly using calorimeters. In the IRT, a special adiabatic calorimeter (see Section 4.0) was required because of low power level operation. In the VOTA, calorimeter operation will be possible at full power level when heat generation rates will be sufficiently high to generate readily-measurable temperature gradients. In such calorimeters, the steady-state energy deposition rate $q$ is proportional to the temperature difference between the receptor and the heat sink:

$$
q=\alpha\left(T_{r}-T_{s}\right)
$$

Various geometric arrangements can be employed to create such a calorimeter, with each having specific limitations and shortcomings depending on the physical limitations and environmental conditions in which it is to be employed. Rather than selecting a single type of calorimeter, it was judged desirable to utilize two different types of devices that had been successfully employed in other reactors. In both types of detectors, stainless steel will be the receptor material. Any difference in measurements will be an indication of potential biases or shortcomings that must be resolved in establishing the actual energy deposition rates in the FTR. In addition, the calorimeter measurements must be in agreement with the results obtained from ionization chambers and other detectors to confirm the overall validity of the measurements program.

\subsection{Design of Whitshell Calorimeter}

Personnel at the Canadian Whitshell Nuclear Research Establishment had successfully constructed and operated calorimeters in heavy water reactors [1] and agreed to design and construct a set of calorimeters for use in the FTR. 
These are referred to as Whitshell calorimeters, and the design is illustrated in Figure 7.1. The calorimeter consists of a stainless steel sensor approximately two inches long and 0.22 inch in diameter, suspended in a stainless steel jacket that is 0.43 inch in diameter. The heat generated in the stainless steel sensor must be transferred to the jacket through the argon-filled annulus. Thermocouples embedded in the sensor and the jacket measure the temperature difference. The jacket will be cooled by the reactor sodium in which it is immersed. All outside surfaces of the calorimeter are made of stainless steel in order to be compatible with the high temperature sodium.

\subsection{Calibration and Operation of the Whitshell Calorimeter}

The fundamental calorimeter equation given in Section 4.2 may be rewritten slightly as follows:

$$
\frac{m d T_{s}}{d t}=m \dot{q}-K\left(T_{s}-T_{j}\right)
$$

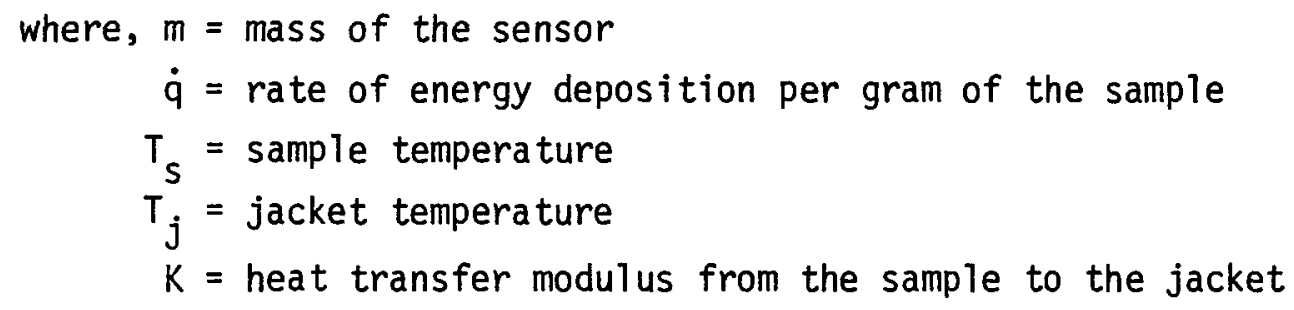

In operation, an equilibrium condition is reached in which, for a specific sample-jacket $\Delta T$, the rate of loss equals the rate of energy gain, $\dot{q}$. This mode of operation is called isothermal, and the rate of temperature change with respect to time is zero. For the VOTA calorimeters, the heat input rate is large enough so that the time to come to equilibrium is small. Also, the sample-jacket $\Delta T$ is large in contrast to the IRT calorimeter, which would have required many hours to achieve a significant, equilibrium $\Delta T$.

For steady-state operation, the VOTA calorimeter equation is:

$$
\dot{q}=\frac{K}{m}\left(T_{s}-T_{j}\right)
$$




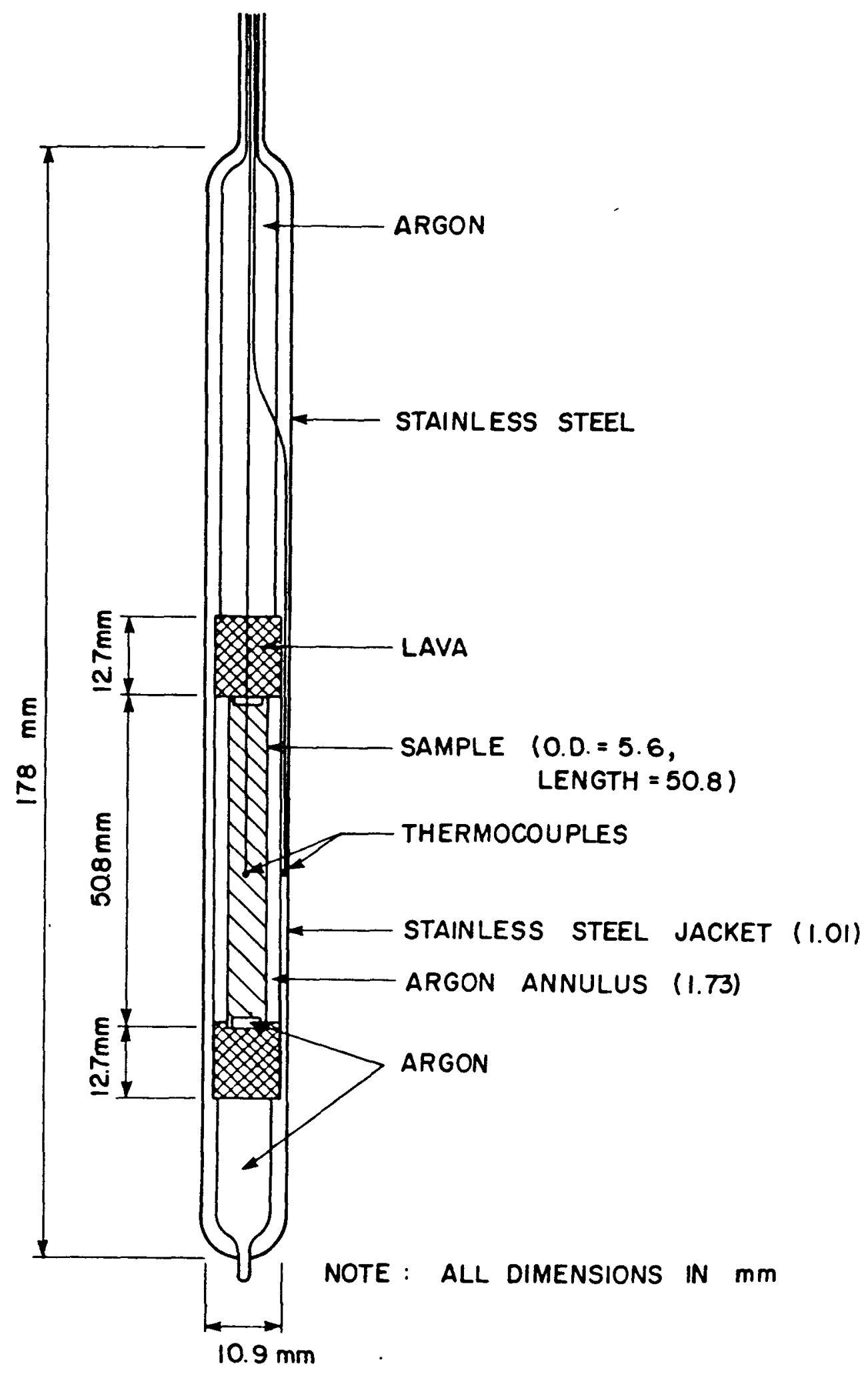

FIGURE 7.1. Whiteshell High Temperature Calorimeter, Line Drawing 
Calibration of the VOTA calorimeters consists of measuring the heat transfer modulus, $K$. The Whitshell calorimeters were calibrated by heating them to approximately $600^{\circ} \mathrm{C}$ in a furnace and then quickly withdrawing them and c00ling them with argon gas. The transient temperatures were measured with thermocouples. Figure 7.2 shows $T_{s}$ and $T_{j}$ as a function of time for one of the calibration measurements. During the transient, the calorimeter equation becomes:

$$
\frac{d T_{S}}{d t}=\frac{K}{m C}\left(T_{s}-T_{j}\right)
$$

A plot of the sample rate of cooling versus the sample-jacket $\Delta T$ from the data in Figure 7.2 yields a linear graph (Figure 7.3 ) whose slope is $\mathrm{K} / \mathrm{mC}$. Multiplying the slope of this plot by the sample specific heat $C$ (which is temperature dependent) yields the calibration constant, $\mathrm{k} / \mathrm{m}$. The values of $\mathrm{K} / \mathrm{m}$ for the two Whitshell calorimeters were evaluated to be 7.82 and 7.9 watts $/ \mathrm{gm}-{ }^{\circ} \mathrm{C}$ with an accuracy of approximately $2 \%$.

\subsection{Proposed Experiment}

The two Whitshell calorimeters are located in the VOTA near the core midplane elevation with one of the calorimeters on the core side and the other on the reflector side in order to obtain radial gradient information at that location. The calculated gradient across the VOTA is expected to be a factor of 1.72, which is sufficiently large to expect significantiy different responses from the two calorimeters. Data will be obtained during steady-state operation of the reactor at various power levels over the operating range of the calorimeters up to the full operating power level of $400 \mathrm{~mW}$. Data will be taken during several operating periods as long as the calorimeters continue to perform satisfactorily. 


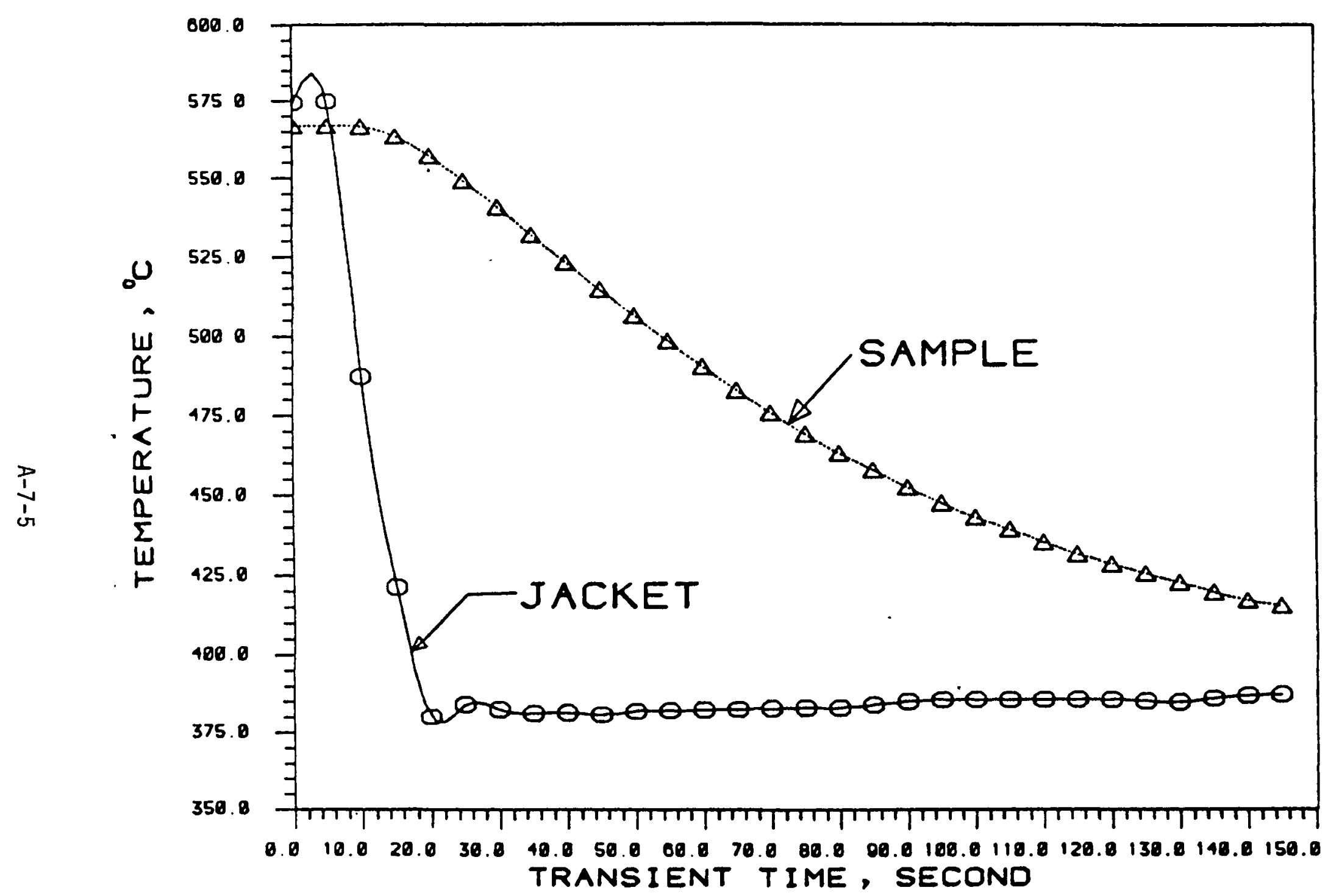

Figure 7.2. Temperature vs Transient Time During Calibration for Whiteshell Calorimeter No. 2, Run No. 3. 


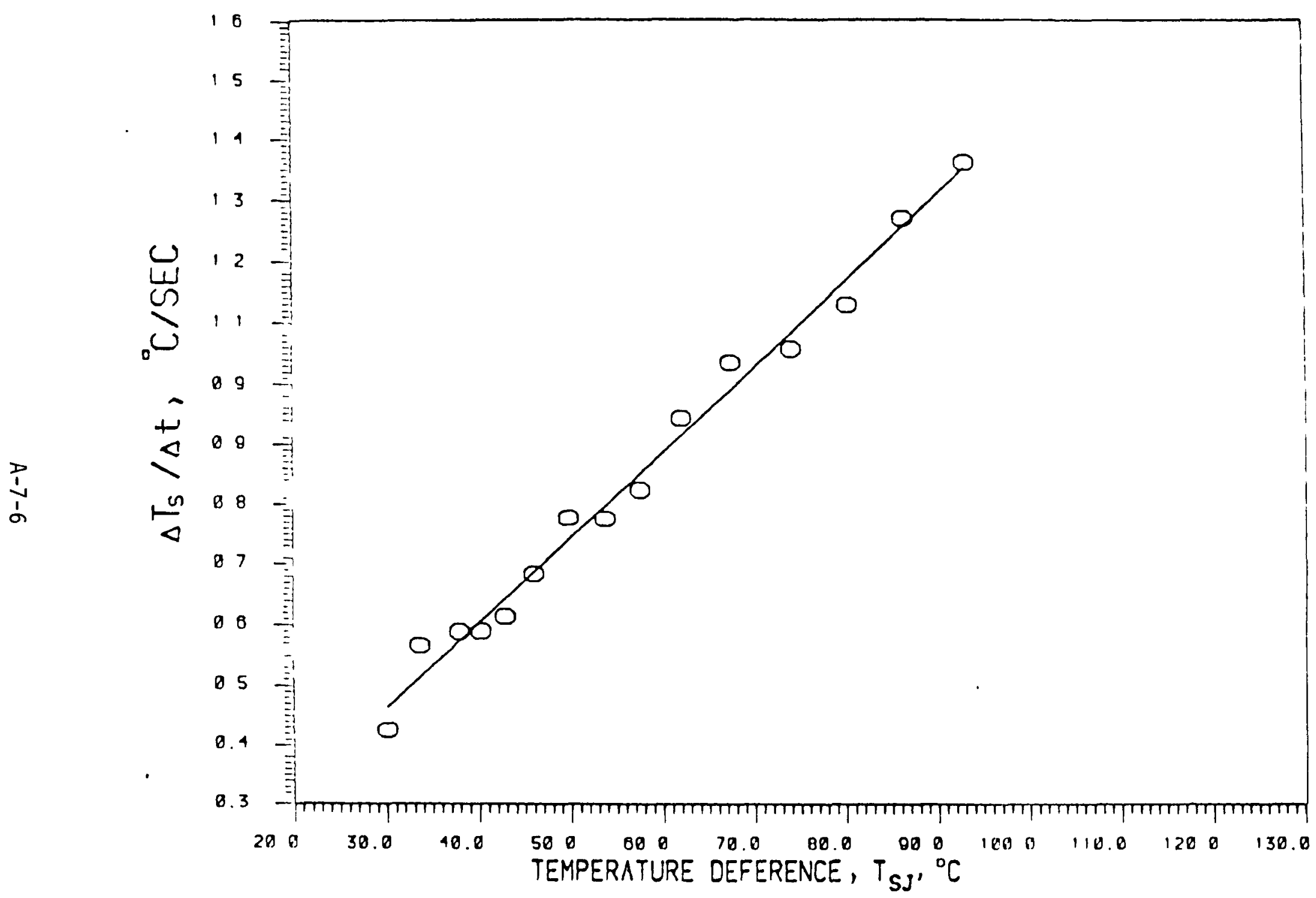

Figure 7.3. Sample Cooling Rate vs $\Delta T$ Between Sample and Jacket, Calorimeter No. 2, Run No. 3. 


\subsection{Expected Results}

The calculated energy deposition rate in stainless steel at the midplane elevation of the VOTA is about 2.6 watts per gram. Thus, it is anticipated that the Whitshell calorimeters will give results of this approximate magnitude when appropriate consideration is given to the gamma ray field gradient that is expected to exist. The results of these calorimeters will be used together with the other gamma ray field measurements to define the energy deposition rates together with the uncertainty.

\subsection{Acknowledgements}

The Whitshell calorimeters were procured by M. R. Wood of HEDL through the cooperation of Dr. K. K. Mehta of the Canadian Whitshell Nuclear Research Establishment. The cooperation of Mr. Mehta is especially appreciated. Evaluation of the calibration data was carried out at HEDL by Dr. E. L. Tang.

\subsection{Reference}

1. AECL-3795, "Radiation Dosimetry in WR-1 Reactor, Part 1, Calorimetry," K. K. Mehta and A. N. Stadkik (April 1971). 


\subsection{VOTA HEDL CALORIMETERS}

\subsection{Introduction}

In addition to the Whitshell calorimeters described in Section 7.0, special VOTA calorimeters were designed based on similar arrangements that had been used successfully in EBR-II. It was desired to use calorimeters of significantly different basic design to eliminate the possibility that a common bias would compromise the results. If the results of the two different calorimeters are in agreement, and also are in agreement with ionization chamber and other gamma ray experimental results, it can safely be assumed that the gamma ray field is defined accurately without bias. It is more likely that an array of values will be measured because of the limitations and biases associated with the devices. An evaluation of all of the results is expected to provide a more accurate determination of the gamma ray field than any one method alone.

\subsection{Design and Construction of the HEDL Calorimeter}

As in the case of the Whitshell calorimeter, the HEDL calorimeter is an isothermal design. It is based on experience gained at EBR-II, [1] but the design is significantly different because of different physical requirements. The design of the HEDL calorimeter is illustrated in Figure 8.7. It is designed such that heat transfer is by conduction down the sensor and out the base to the surrounding sodium. For this type of calorimeter, the heat conduction equation, assuming no conductive, convective or radiative losses through the sides, is given by:

$$
T(x)-T_{b}=\frac{\dot{q}}{k} P\left(L x-x^{2} / 2\right)
$$

where, $T(x)=$ the temperature of the base

$\dot{q}=$ the energy deposition rate in watts/gm

$k=$ the sensor thermal conductivity

$P=$ the sensor density

$L=$ the sensor length 


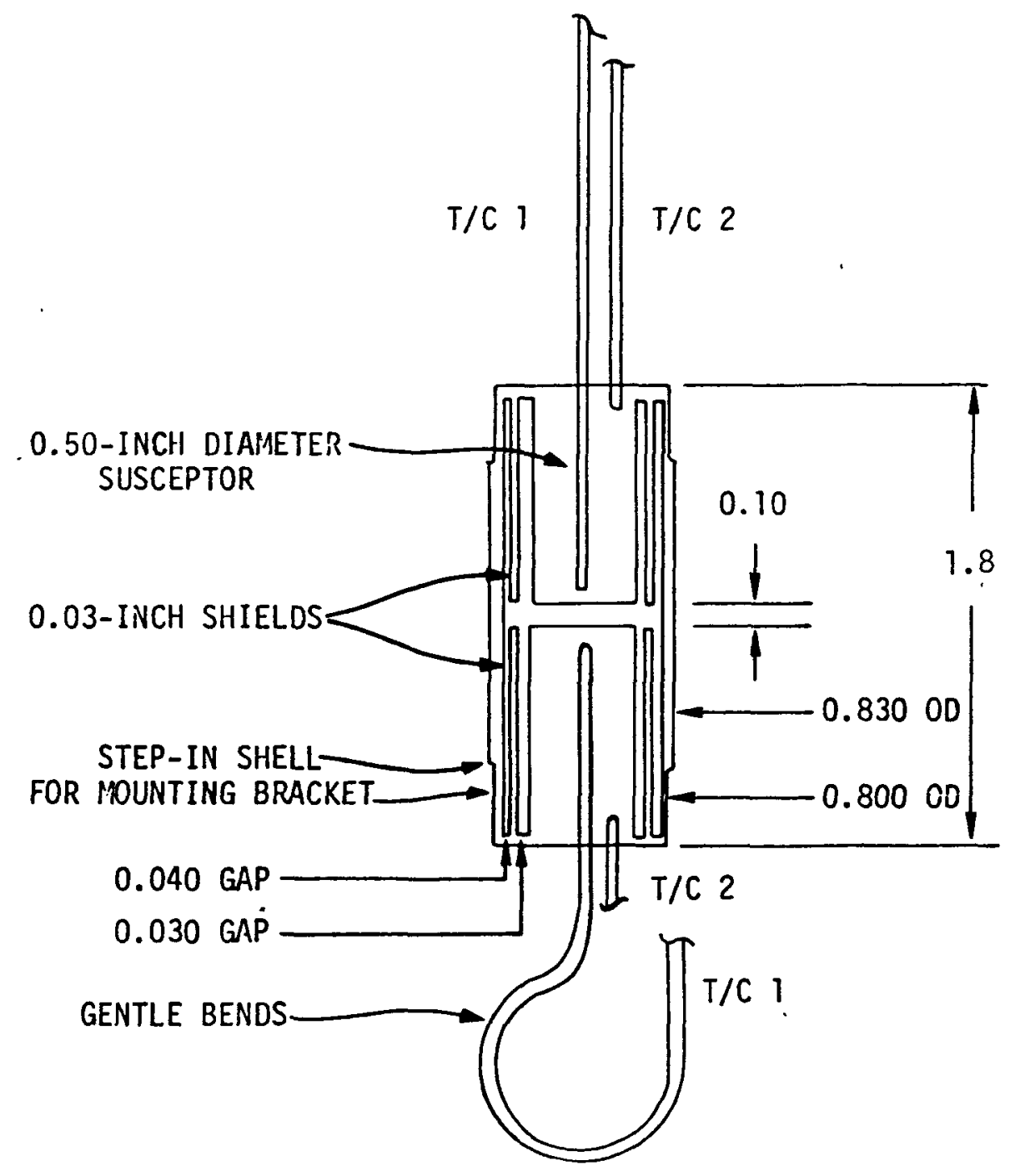

FIGURE 8.1 VOTA Calorimeter 
Convective losses can be minimized by evacuating the calorimeter; however, radiative losses cannot be eliminated. Radiative losses can be written as:

$$
\text { heat loss } \alpha\left(T_{1}^{4}-T_{2}^{4}\right)
$$

where, $T_{1}$ and $T_{2}$ are the surfaces of interest.

For surfaces having temperatures in the range of $700^{\circ} \mathrm{F}-1000^{\circ} \mathrm{F}$ range, radiative losses are significant. They are minimized in this calorimeter design through the use of heat shields. In this manner, the major radiative loss is from the shield to the outside shell, rather than from the sensor. By design, the shield temperatures are close to the sensor temperature, greatly reducing radiative losses from the sensor. Placing two sensors in the same jacket further reduces radiative losses because the two sensor tips should be approximately the same temperature. In addition, this procedure permits two measurements to be made at essentially the same location. Thermocouples are embedded near the tip and base of each sensor. As in the case of the whitshell calorimeters, all outer surfaces of the calorimeter are made of stainless steel in order to be compatible with the high temperature sodium environment of the FTR.

\subsection{Calibration of the HEDL Calorimeters}

A computer program was written by Dr. H. G. Johnson of HEDL for the heat transfer analysis of the HEDL calorimeter to provide a basis for its design. This program is also suitable for data analysis of the completed design. In addition to as-built dimensions, the program also requires the temperature dependent thermal conductivity of the sensor material. Since this parameter is essential to the proper evaluation of the data, a sample of the sensor stainless steel was sent to the Properties Research Laboratory at Purdue University for analysis. [2] In addition, as an independent evaluation of the operation of the calorimeter, transient data of the sensor and base 
cooldown rates will be measured following reactor scrams. The data will be analyzed as for the Whitshell calorimeter and permit an independent measurement of the FTR energy deposition rates.

\subsection{Experiment}

The HEDL calorimeters are located in the VOTA near core midplane elevation, and at positions 15 inches above and below core midplane, near the top and bottom of the fueled region. In this way, additional data on the axial shape of the energy deposition distribution will be obtained. Two calorimeters are located at the core midplane elevation, $180^{\circ}$ apart, to measure the radial gradient across the VOTA.

\subsection{Expected Results}

Results of the HEDL calorimeter measurements are expected to be comparable to those from the Whitshell calorimeters. That is, an energy deposition rate of approximately 2.6 watts/gm and a radial gradient of approximately 1.7 . In addition, the calorimeters located near the top and bottom of the core will give data on the axial distribution of the energy deposition rate. Although it will be at the lower limits of the sensitivity of the calorimeters, they will be used to measure the shutdown decay heat transient in the reactor. This will be supplementary measurement to those made by the ionization chambers and self-powered detectors to improve the experimental data and eliminate biases. If reasonable consistency is achieved in the measurements, the uncertainty in the energy deposition rate will be sufficiently small to meet program goals.

\subsection{Acknowledgements}

Detailed design of the HEDL calorimeters was performed by M. R. Wood, who also follows their construction and installation in VOTA. 


\subsection{References}

1. ANL-R 760016, Gamma Heat Measurements in EBR-II Using Passive Calorimeters, C. C. Price (February 1976).

2. PRL 167, Thermal Conductivity and Specific Heat of a 316 Stainless Steel, H. Groot and R. E. Taylor (September 1978). 


\subsection{THERMAL EXPANSION DIFFERENCE DETECTORS}

\subsection{Introduction}

The gamma ray measurements described in the previous sections are limited to two locations within the core, namely core position 3202 where the IRT is to be located and core position 1610 where the VOTA is to be located. Those two positions permit the use of a variety of detectors because of special environmental conditions and, most importantly, permit the use of active devices with instrument leads. For these reasons, relatively extensive measurements are planned in those positions. There is also a desire to make gamma ray measurements throughout the core and reflector for further validation of the analytical method. Of special interest are regions where steep gamma ray source gradients are known to exist, such as near control rods. The only test vehicles that can be placed in a number of reactor positions are characterizers, and only passive sensors can be placed in characterizers because instrument leads are not possible. The only known passive gamma ray sensor that can operate in the characterizer environment is a Thermal Expansion Difference (TED) detector. [1] This device does not measure gamma ray energy directly, but deforms to record the maximum temperature that is reached. The gamma ray energy deposition must be inferred from this maximum temperature and the heat transfer characteristics from the TED detector to its surroundings. Although the precision of the measurement is expected to be limited, the spatial detail that can be achieved is expected to be of material value in improving analytical techniques.

\subsection{Design and Construction of TED Detectors}

Design of the TED detectors is illustrated in Figure 9.1. Outside diameter of the capsule was selected to fit within the sensor pins to be used in the characterizers. Sodium is encapsulated in the stainless steel shell of the TED detector. When the sodium in the capsule is heated, it expands and 


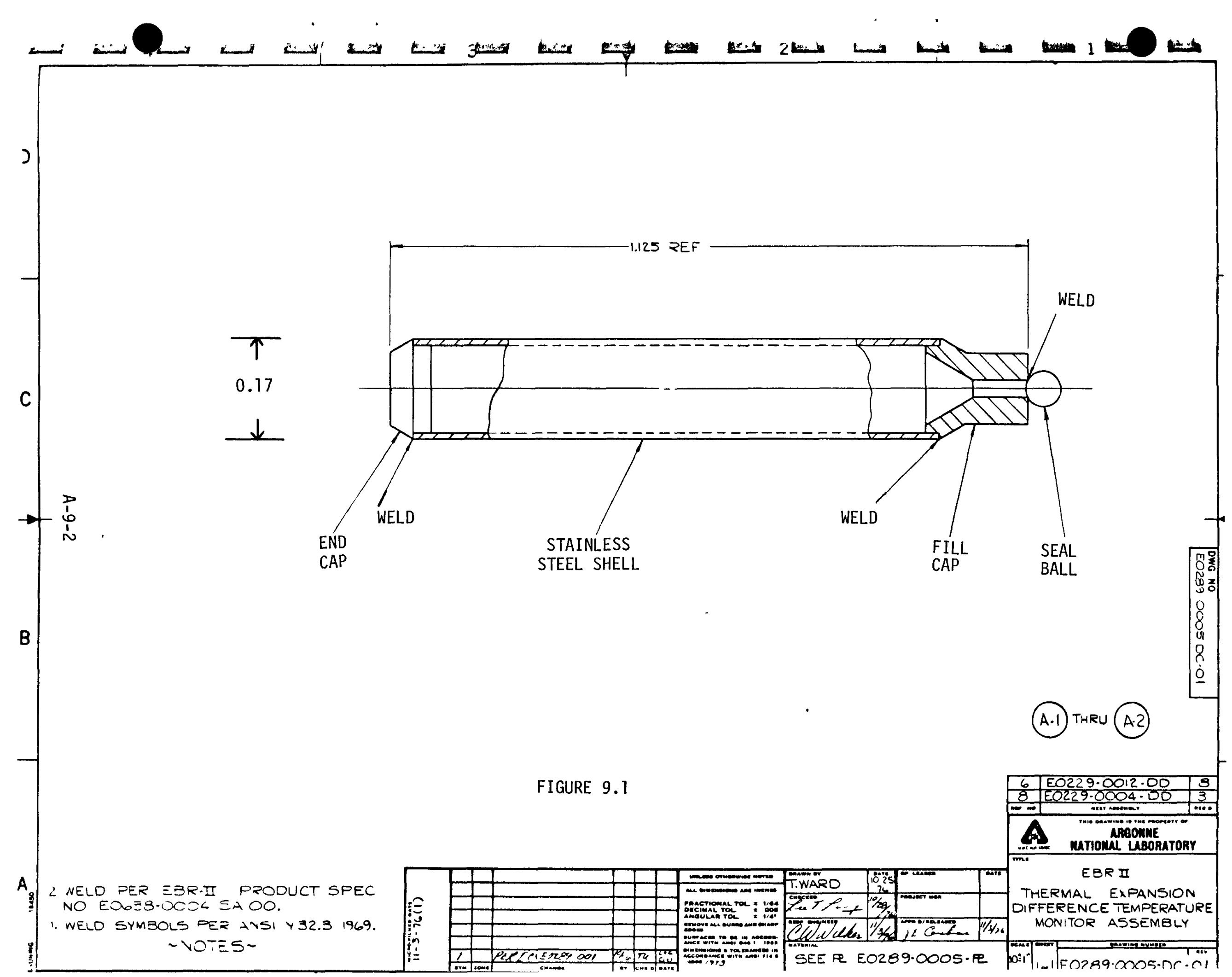


plastically deforms the capsule. The difference in volume displaced by the deformed capsule and the as-built capsule is directly related to the maximum temperature reached by the sodium.

\subsection{Calibration of TED Detectors}

The volume of each TED detector is carefully measured and recorded for postirradiation use. A set of detectors is taken from the array fabricated in a production run and heated to various selected controlled temperatures to provide a calibration curve for the production run. Results of the calibration run for the detectors being employed in this experiment are shown in Figure 9.2. The irradiated capsules will be processed in a similar manner to determine the maximum temperature attained by each.

\subsection{Proposed Experiment}

Two pins, each containing seven TED detectors at various axial heights to investigate the axial distribution of gamma heating, will be placed in each characterizer. These pins will be diametrically opposite each other in the characterizer to investigate gradients across the characterizer and, whenever possible, the characterizers will be located in radially adjacent locations in the core so that inter-row gradients may be investigated, as well as discontinuities between different types of characterizers, such as fueled and reflector.

\subsection{Expected Results}

The temperature profile generated by the array of TED detectors will be directly related to the local sodium coolant temperature and the energy deposition distribution. Three-dimensional diffusion theory calculations provide an estimate of the magnitude of the gamma ray energy deposition rate throughout the reactor system. Local sodium temperatures are predicted based on the fission rate distribution in the core. Final prediction of the TED detector temperature at any 


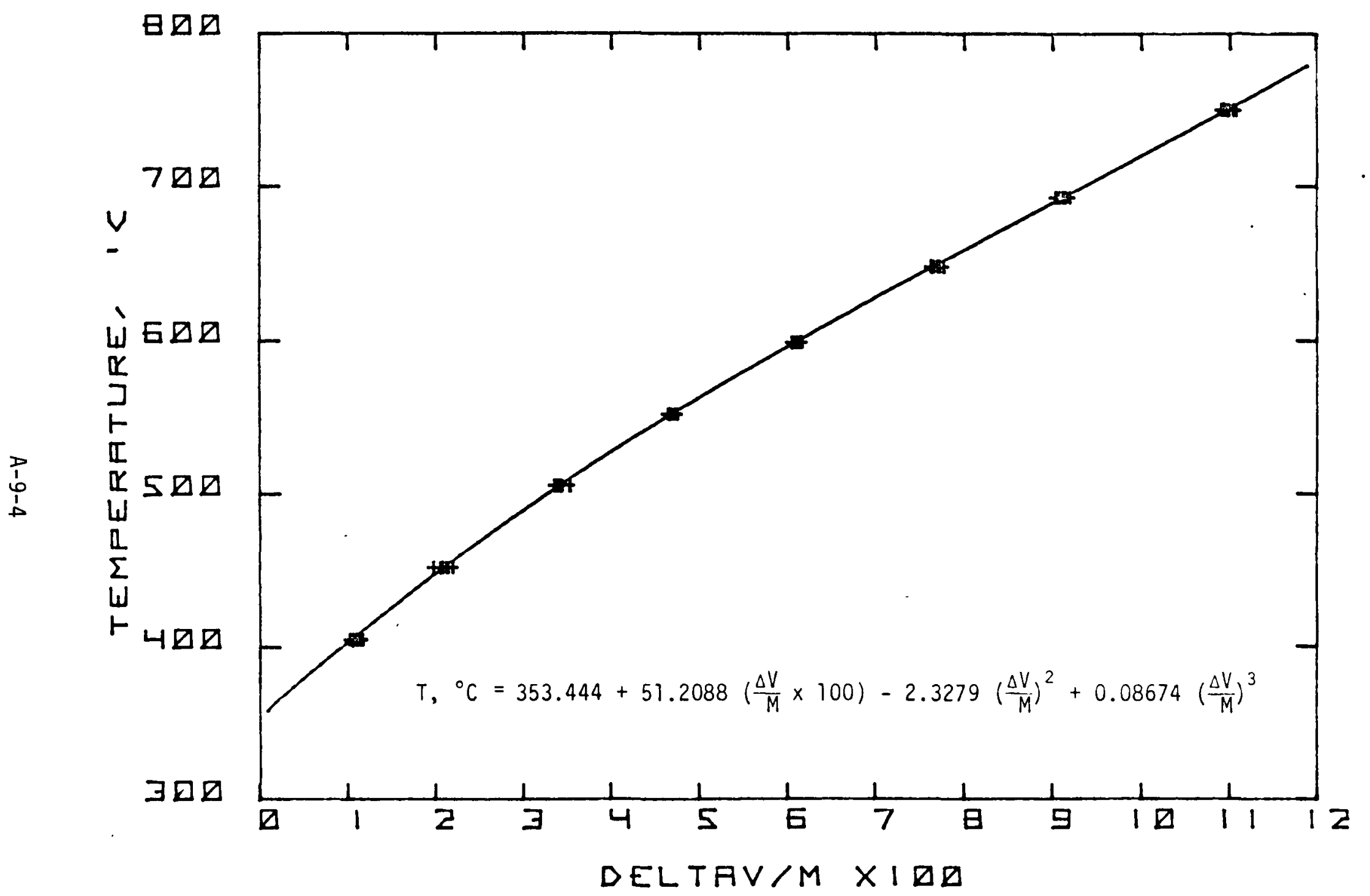

Figure 9.2. Calibration of TED Batches H-M (August 1977). 
given location requires a heat transfer calculation to estimate the temperature difference between the TED detector and the local sodium temperature. These results will then give a prediction of the TED detector temperature distribution for comparison with the measured values. Comparison of the measured and predicted results will provide another basis for evaluating the accuracy of the analytical techniques used for gamma ray calculations in FTR.

\subsection{Reference}

1. ANL-R 760016, Gamma Heat Measurements in EBR-II Using Passive Calorimeters, C. C. Price (February 1976). 


\section{B. SHIELD CHARACTERIZATION}

\section{INTRODUCTION}

The sodium-cooled Fast Test Reactor (FTR) in the FFTF is of the loop type that contains only metal shields within the reactor vessel, with external concrete walls preventing activation of secondary sodium. The metal shields within the reactor vessel are required to protect structural components for the design lifetime of the facility. The reactor shield system consists of both fixed and replaceable shields. For example, each core component includes a lower axial reflector and shield that are removed with the core component at the end of its useful life. The primary radial shield consists of reflectors, which are also to be replaced at the end of their useful lives. The fixed radial shield is designed to last for the lifetime of the facility by limiting the structural requirements on the materials. Through a combination of replaceable and fixed shields and distance, key structural components, such as the core support structure, the radial restraint mechanism, the reactor vessel, the reactor cover, the instrument trees, and the in-vessel handling machines, will not need to be replaced over the lifetime of the facility because of radiation damage. Measurement of the actual performance characteristics of the reactor shield system is included in the Reactor Characterizer Program to establish the radiation environment in which the structural components do reside at full power.

The reactor shield also reduces the neutron flux in the region of the InVessel Storage (IVS) modules sufficiently so that stored fuel can be cooled satisfactorily. The storage positions have very low flow rates, which must cool not only the fission products in the irradiated fuel but also the heat generated by fissions induced in the fuel. Therefore, part of the reactor shield characterization program will be to establish the neutron environment in the IVS modules both with and without stored fuel present. The measurements will either establish that fuel can safely be stored in all storage positions, or will establish those positions where heat generation would be excessive under as-built conditions. 
The reactor radial shield also creates the environment in which the Ex-Vessel Flux Monitoring system resides. The shield characterization measurements will establish the nuclear environment in the reactor cavity, including the effect of stored fuel on the environment.

Use of active sensors to characterize the shield performance is not possible; therefore, the program is limited to the use of passive devices. Because the core is the ultimate source of radiation, the shield measurements must inciude core measurements. The core measurements will all be made as part of the neutronics measurements program described in Part I of this report. Many of the neutronics measurements that are to be made external to the reactor core are in support of the shield performance program. Thus, the special characterizer assemblies will provide one source of information. In addition, the two IVS sample holders will be used to make measurements in the IVS modules. Finally, a thimble located in the reactor cavity will be used to characterize the environment external to the reactor vessel. Even though it is not possible to make detailed spatial measurements throughout the reactor, the test vehicles will permit monitoring at key locations and permit interpolation, rather than extrapolation, of results to define environments at structural components of interest. 


\subsection{CHARACTERIZER IRRADIATIONS}

\subsection{Introduction}

The core is the source of radiation whose spectral and spatial distribution must be defined in detail in order to evaluate the performance of the shields. The neutronic characterization of the core is described in detail in Part $A$ and the gamma ray characterization of the core is discussed in Part B. Neutron distribution external to the core has little impact on core neutronics except for the region of the reflector adjacent to the core. A special long center sensor pin was included in the design of characterizers to permit measurements of interest in evaluating the performance of the below core shield.

\subsection{Design of Characterizers}

There are three basic types of characterizer assemblies: fueled, shim and reflector. The fueled and shim characterizers use modified standard ducts and inlet assemblies together with removable handling sockets that permit access to the sensor and provide sensor pin holddown. The ducted type characterizer is illustrated in Figure 1.1. The reflector characterizers use standard sized Inconel reflector and steel shield blocks that have been modified to create openings for sensor pins. The reflector characterizers also have removable handling sockets that permit access to the pins and provide holddown of the sensor pins. The two types of reflector characterizers are illustrated in Figures 1.2 and 1.3. The array of sensor pins within an assembly (shown in Figure 1.4) permit mapping of radial as well as axial gradients throughout the reactor. Figure 1.5 illustrates the relationship of the characterizer measuremnets in the core to the other shielding measurements described in Sections 2 and 3. 
Figure 1.1

CORE CHARACTERIZER

ROWS 1.6 AND IN-CORE-SHIM

$\frac{1}{\dot{1}}$

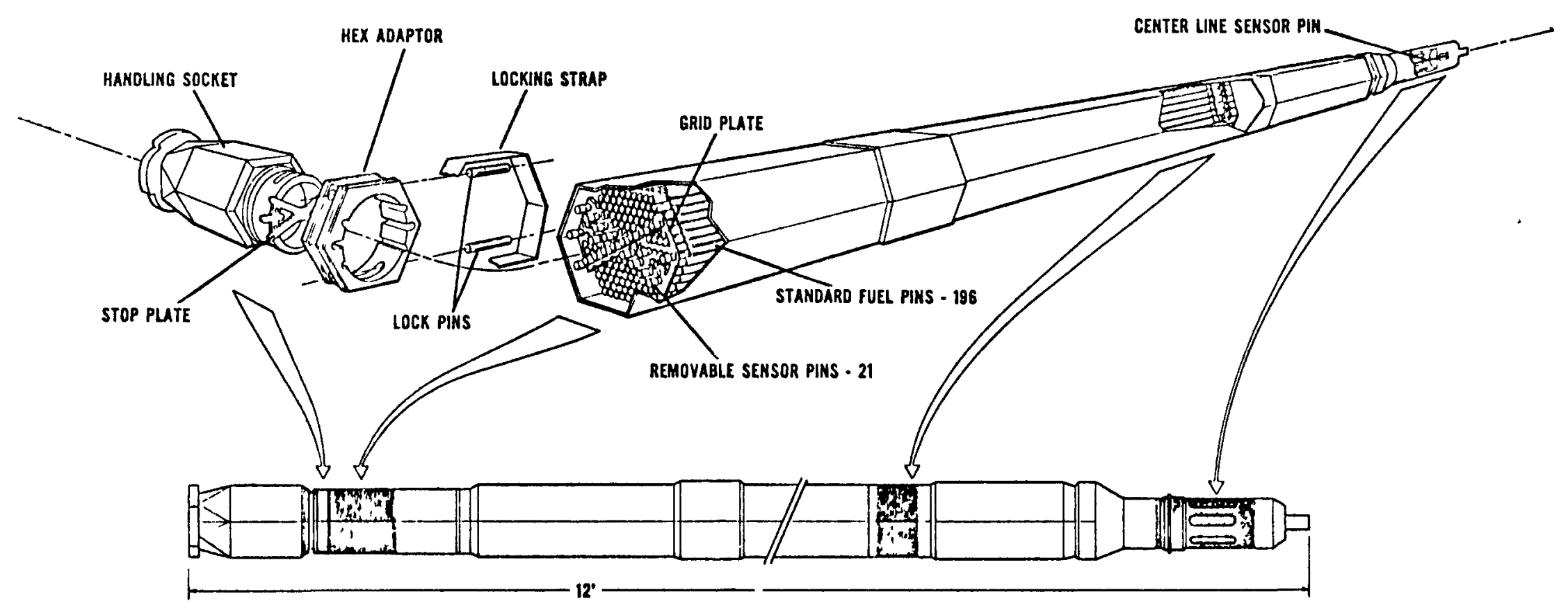




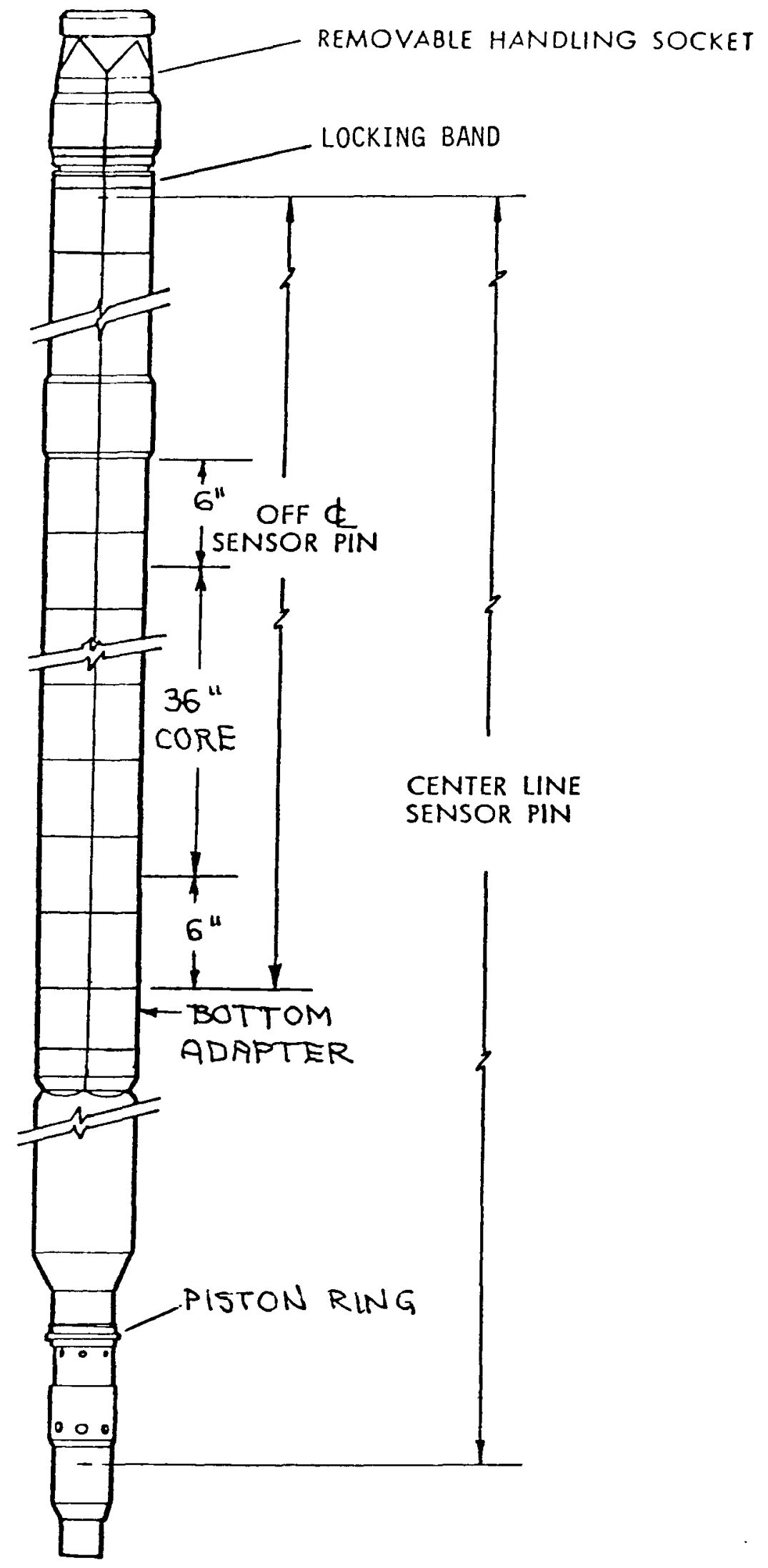

Figure 1.2 - Row 7 \& 8 A Characterizer

$$
\text { B-1-3 }
$$




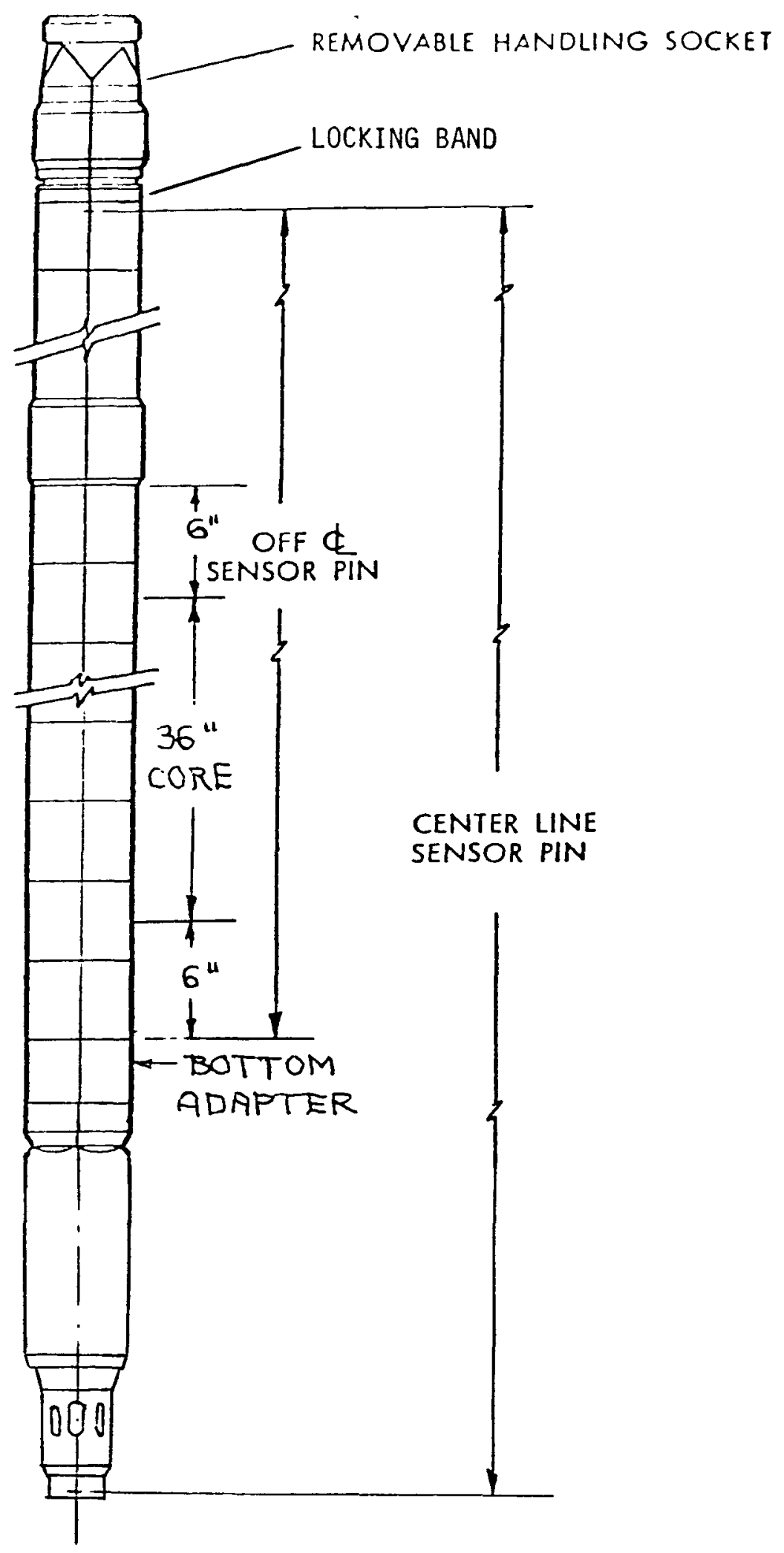

Figure 1.3 - Row $8 B$ \& 9 Characterizer 


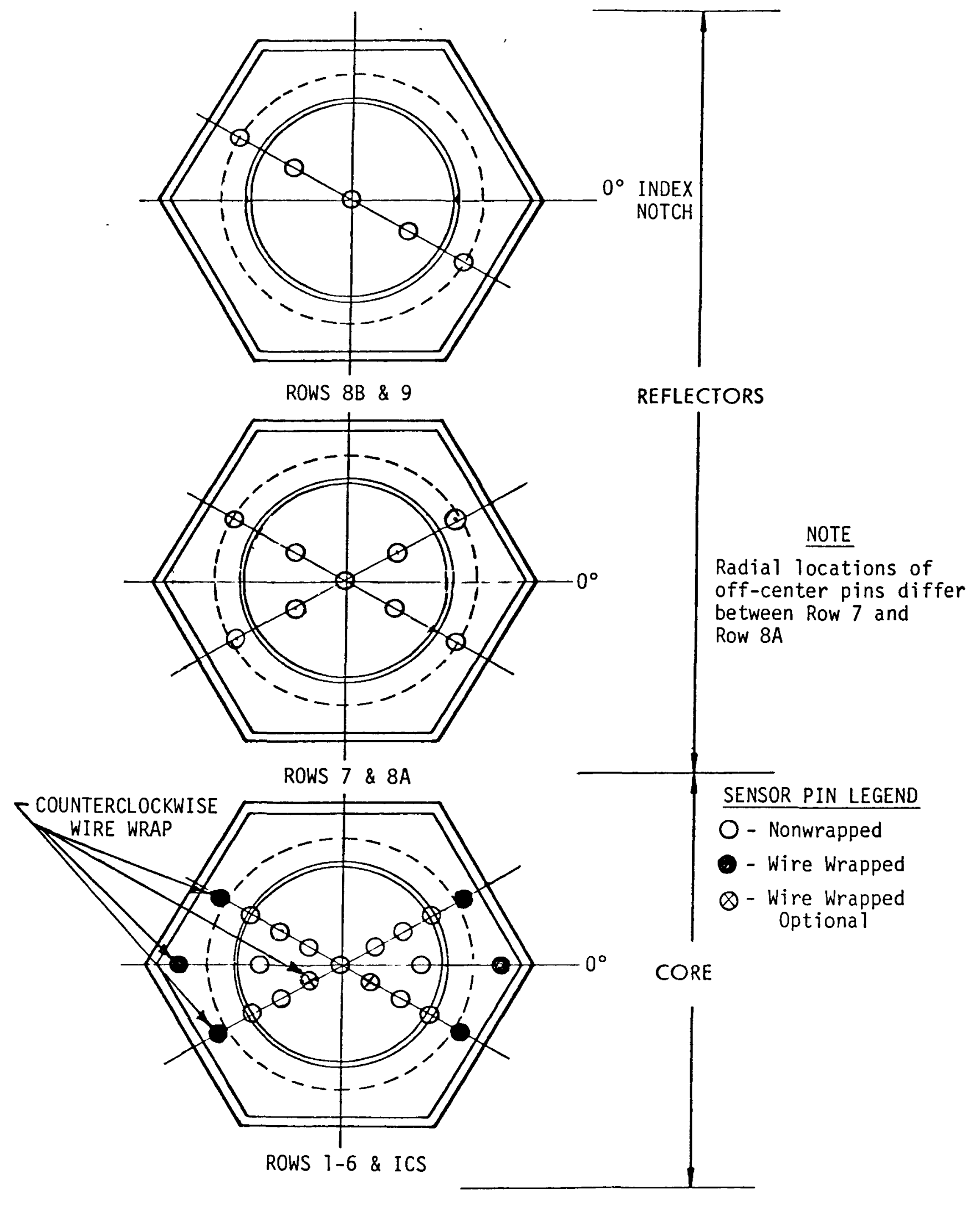

Figure 1.4 - SENSOR PIN PLAN 
Figure 1.5

Relative Positions of Sensors in Characterizers, In-Vessel Storage Module, and Reactor Cavity Thimble.

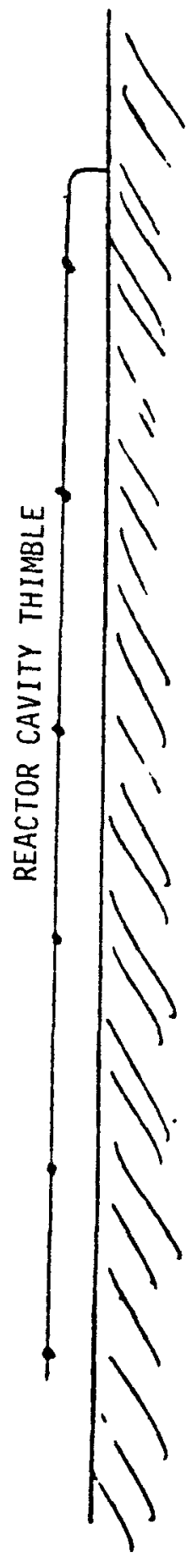

$B-1-6$ 


\subsection{Proposed Experiment}

Two different irradiations are to be made using the characterizers. The first is to be at a power level of 4 MW (one percent of design power) for one day. Low power operation permits use of sensors not possible at higher temperatures and power, and also permits neutronic measurements to be made directly within fueled sensor pins. The second planned irradiation will be at the design power level of $400 \mathrm{MN}$ for an operating time of eight days. The higher fluxes limit the types of sensors that can be employed, but provide information at actual operating conditions and assure adequate activation of sensors at positions far from the core.

The shield measurements included in the neutronics measurements described in Part A consist of a number of limited spectral packages located external to the core. The sensors were chosen to provide as much spectral information as possible within the limitations of the program. In the core, spectral changes are quite 7 imited and small changes are of interest because of the impact they could have on the local fission rate. In the shield, the neutron spectrum changes quite dramatically with distance from the core and the changes are related. Therefore, significant useful data for evaluating attenuation calculations can be obtained from the relatively limited spectral information to be obtained from the radioactivants.

\subsection{Expected Results}

In order to establish the types and sizes of foils that could be used as a function of position in the shield, it was necessary to perform a 3-dimensional diffusion theory calculation to obtain the spatial and energy distribution of the neutron flux. The neutron fluxes were then multiplied together with the individual reaction cross-sections to estimate activity induced as a result of the proposed irradiation. Based on these calculations, the array of detectors was selected. The same calculations provide the expected results. Any 
gross or systematic differences between the predicted and measured reaction rates will provide a basis for more detailed evaluation. Differences between measured and calculated values could be associated with nuclear data, either transport or activation cross-sections, with the analytical methods employed, or with modeling limitations. Thus, in addition to providing a direct measure of the nuclear environment at specific shield locations, the measurements will provide a basis for improving shielding calculations in this system.

\subsection{Acknowledgements}

The characterizers were designed and procured under the direction of R. E. Keyes. The shielding measurements were integrated with the core neutronics measurements by $\mathrm{J}$. A. Rawlins, who was responsible for the overall radioactive sensor program. R. S. McBeath worked with laboratory personnel to ensure the timely and accurate placement of samples within the characterizers. 


\subsection{IN-VESSEL STORAGE MEASUREMENTS}

\subsection{Introduction}

Each of the three reactor sectors serviced by an Instrument Tree and an InVessel Handling Machine contains a core component storage module that is located between the core barrel and the reactor vessel. The storage module in each sector contains 19 storage positions plus a transfer position that can be accessed by the Closed Loop Ex-Vessel Machine (CLEM) to load fuel into and out of the reactor vessel. Each storage position consists of a steel cylindrical sleeve 6.4 inches inside diameter that intersects the upper and lower support plates. The tapered shoulder of the core component rests on the tapered penetration through the lower plate, with the tang of the component residing in an inlet plenum. Coolant from the inlet plenum flows through the assembly by natural convection. Heat in the stored component consists of the decay of isotopes plus the energy associated with neutron events. In the case of stored fuel, the decay heat associated with fission produces could be as much as $10 \mathrm{~kW}$. Therefore, it must be assured that the energy associated with fission events caused by the neutron flux leaking through the radial shield is within the limits established by natural convection cooling.

A second item of interest associated with stored fuel is the effect on the response of the Ex-Vessel Flux Monitoring (EVFM) system. Sensors for the EVFM system are located in graphite blocks supported from the wall of the reactor cavity. The three graphite moderator blocks are at the midplane elevation of the core and at approximately $120^{\circ}$ apart, each being near an inlet sodium pipe. Design calculations for the reactor shield indicate that the response of the fission counters and boron triflouride tubes in the graphite moderators will increase by about a factor of six with fully loaded storage modules when compared to empty modules. In addition, the calculations indicate that the neutron spectrum in the reactor cavity will be much harder with stored fuel present, increasing leakage into the head compartment. Experimental confirmation of these predictions is also of interest. 


\subsection{Design of Sample Holder}

An illustration of the design of the In-Vessel Storage Sample Holder (IVS-SH) is shown in Figure 2.1. The most important feature of the IVS-SH is the handling socket. This handling socket permits transfer by the same grapple that will pick up the characterizers and, like the characterizer handling sockets, is removable to provide access to the sensor pin. The IVS-SH contains only a single, centrally located sensor pin, which in turn contains four packets of materials. Because it does not have to interface with other components, a simple cylindrical duct is used and no load pads are required.

\subsection{Proposed Experiment}

The two IVS sample holders are to be irradiated during the eight day run at a power level of $400 \mathrm{MW}$ during which the characterizers will be irradiated. One of the IVS-SH's will be placed in the transfer position of a module containing stored fuel, and the other will be in the transfer position of a module with no stored fuel. The module with stored fuel will contain as many fuel assemblies as can be made available at the time of the irradiation. These will be loaded in decreasing order of importance insofar as their impact on the flux environment at the transfer location. During the irradiation, the IVS-SH will reside in core components pots, as required for the transfer position. The IVS-SH will be retrieved by CLEM as soon after shutdown of the reactor as possible, and transferred to the IEM cell where the sensor pin will be removed and cut up. The sensor packages will be shipped to the laboratory area for evaluation.

There will be four sensor packages in each of the IVS-SH sensor pins. In each pin, one package will be $122 \mathrm{~cm}$ above core midplane, one $45.7 \mathrm{~cm}$ above core midplane at the fuel-reflector interface elevation, one at core midplane elevation, and one $118 \mathrm{~cm}$ below core midplane. The latter position is as close as possible to the weld joining the support skirt and the lower core support structure forging. 


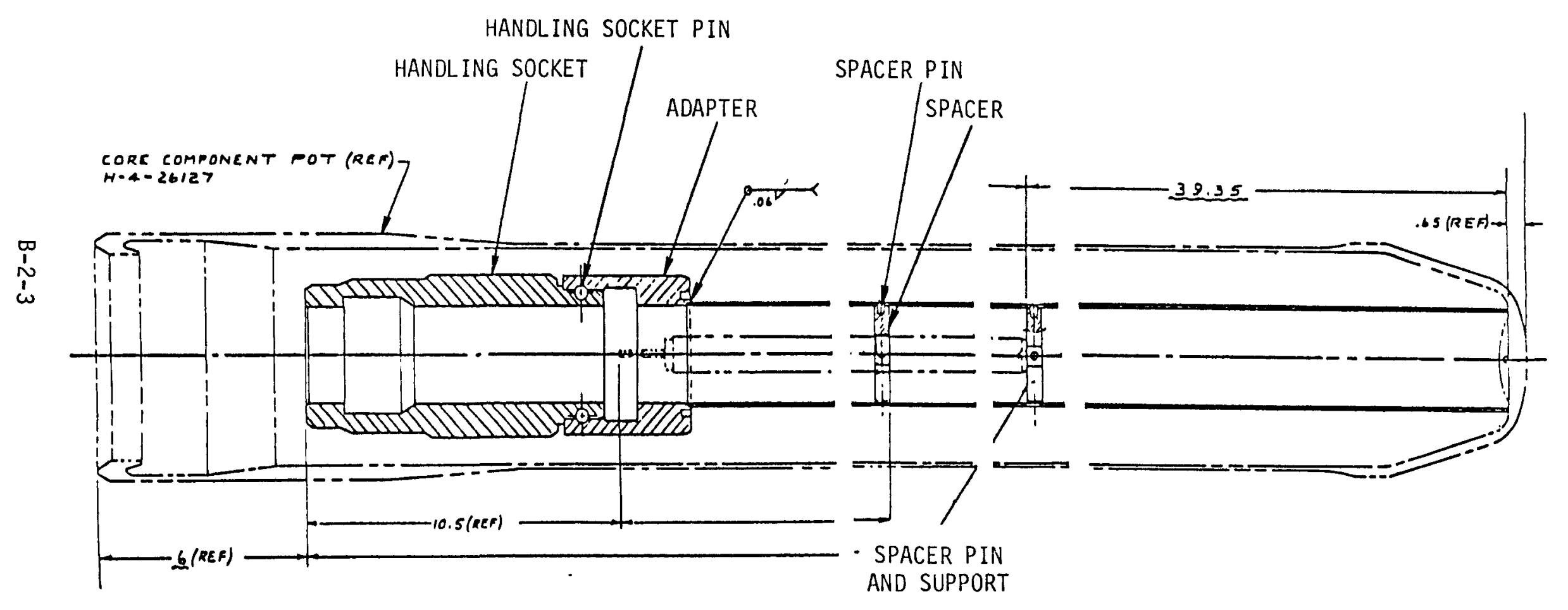

Figure 2.1 In-Vessel Storage - Sample Holder - Partial View. 
A11 four sensor packages in each IVS-SH will contain seven different radioactivants to provide an indication of the neutron flux spectrum as well as the flux intensity. The reactions to be used include: ${ }^{181} \mathrm{Ta}(n, \alpha),{ }^{59} \mathrm{Co}(n, \alpha),{ }^{58} \mathrm{Ni}(\mathrm{n}, \mathrm{p})$, ${ }^{58} \mathrm{Fe}(n, \alpha),{ }^{2} \mathrm{Na}(n, \alpha),{ }^{50} \mathrm{Cr}(n, \alpha)$, and ${ }^{197} \mathrm{Au}(n, \alpha)$. Because the half-life of the ${ }^{24} \mathrm{Na}$ that will be produced is only 15 hours, it is essential that the sensors be recovered quickly in order that radioactive counting might begin within a few days.

The sensor packages located at the core midplane elevation and below the core will also contain three Sol id State Track Recorders (SSTR). The fissile material in the SSTR will include ${ }^{239} \mathrm{Pu}, 235 \mathrm{U}$ and ${ }^{237} \mathrm{~Np}$. The infinitely dilute fission rates established by the SSTR measurements will assist in evaluating predictions of fission power induced in stored fuel assemblies.

\subsection{Expected Results}

Both two-dimensional R-Z diffusion theory and discrete ordinates calculations were made to support the design of the radial shield. Calculations were also made with and without stored fuel in the storage modules. Results of these calculations were used to design the sensor packages and provide an estimate of induced activity in the test specimens. Gross of systematic differences between the predicted and measured reaction rates will provide a basis for improving calculational techniques.

\subsection{Acknowledgements}

The In-Vessel Storage Sample Holder was designed and procured by W. P. Stinson. Fabrication of the sensors and sensor packages was expedited by J. A. Rawlins and R. S. McBeath. The contribution of these individuals is gratefully acknowledged. 


\subsection{REACTOR CAVITY MEASUREMENTS}

\subsection{Introduction}

The neutron flux environment in the reactor cavity is of interest for two primary reasons. First, the neutron flux in the reactor cavity is the source of radiation that governed the design of a number of special shields to assure that dose rates in the head compartment would be low. Second, the Ex-Vessel Flux Monitors that provide the nuclear signal used for controlling the reactor at power are located in the reactor cavity. During the design of the radial shield, it became apparent that the neutron flux intensity and spectral distribution would be dependent on the amount of fuel stored in the In-Vessel Storage modules. Measurements in the reactor cavity are desired both with and without stored fuel to evaluate the accuracy of design calculations.

\subsection{Design of Detection System}

No provision was made in the design of the FFTF to permit access into the reactor cavity that would permit convenient introduction and removal of radiation monitors. In order that some measurements might be made, a two-inch diameter thimble was installed through an unused shield plug, WP-1504, which enters the reactor cavity from Cell 534 at an elevation of about $530 \mathrm{ft}-4 \mathrm{in}$. Once through the cavity wall, the thimble bends downward and travels along the reactor cavity wall down to an elevation of about $501 \mathrm{ft}-3 \mathrm{in}$. as illustrated in Figure 3.1. Sensor capsules that are less than 1.44 inches in diameter and 3.68 inches long can be tied together and lowered into the thimble while the reactor is shut down. A shield plug will be installed to the opening through the reactor cavity wall. After reactor operation and irradiation of the specimens in the capcules, the chain of capsules can be pulled out during the subsequent shut down.

The capsules are made of carbon steel in order to prevent galling on the thimble wall during insertion and removal and to minimize handling problems associated with activation. The capsule design is illustrated in Figure 3.2. This design 


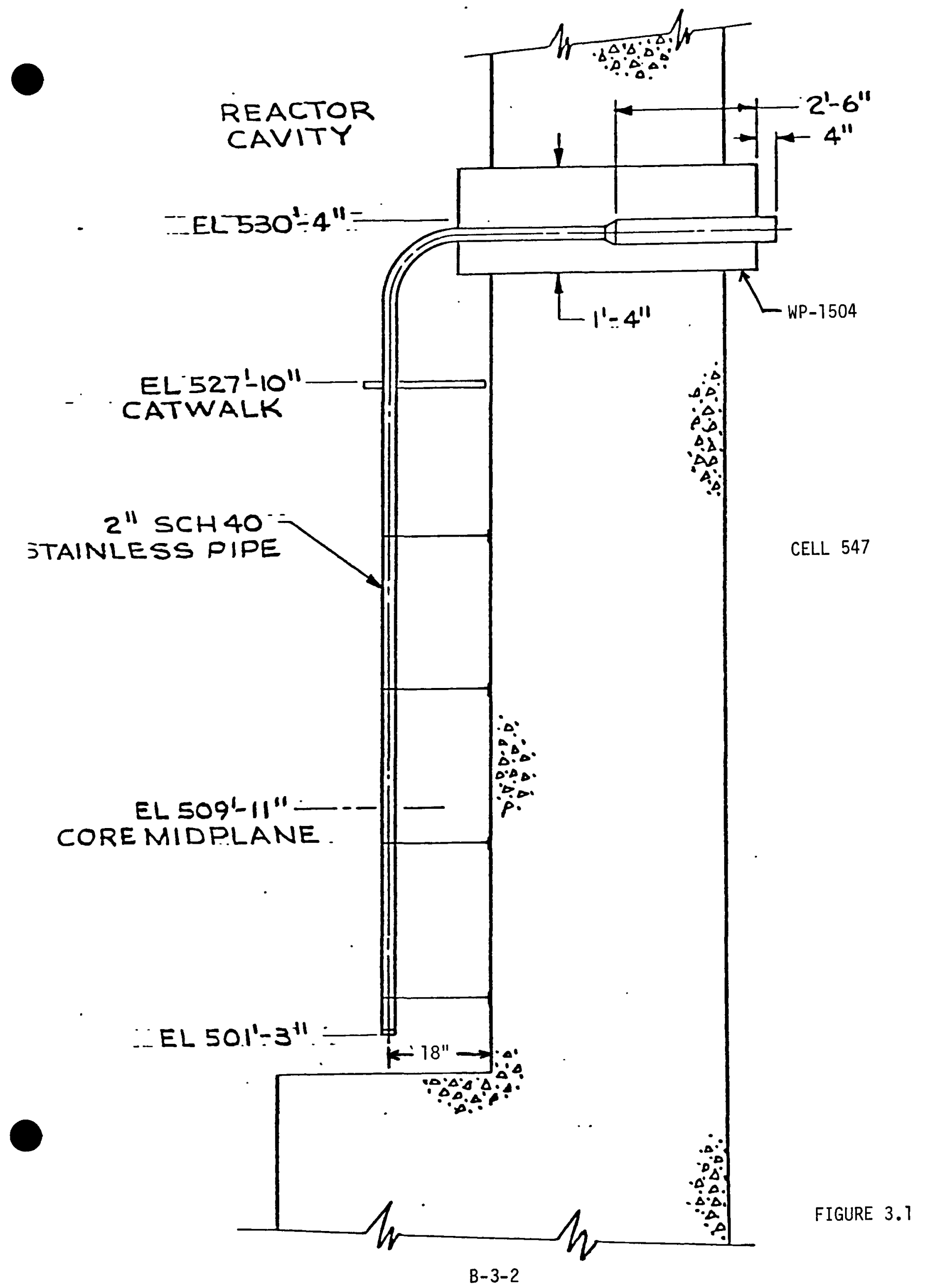




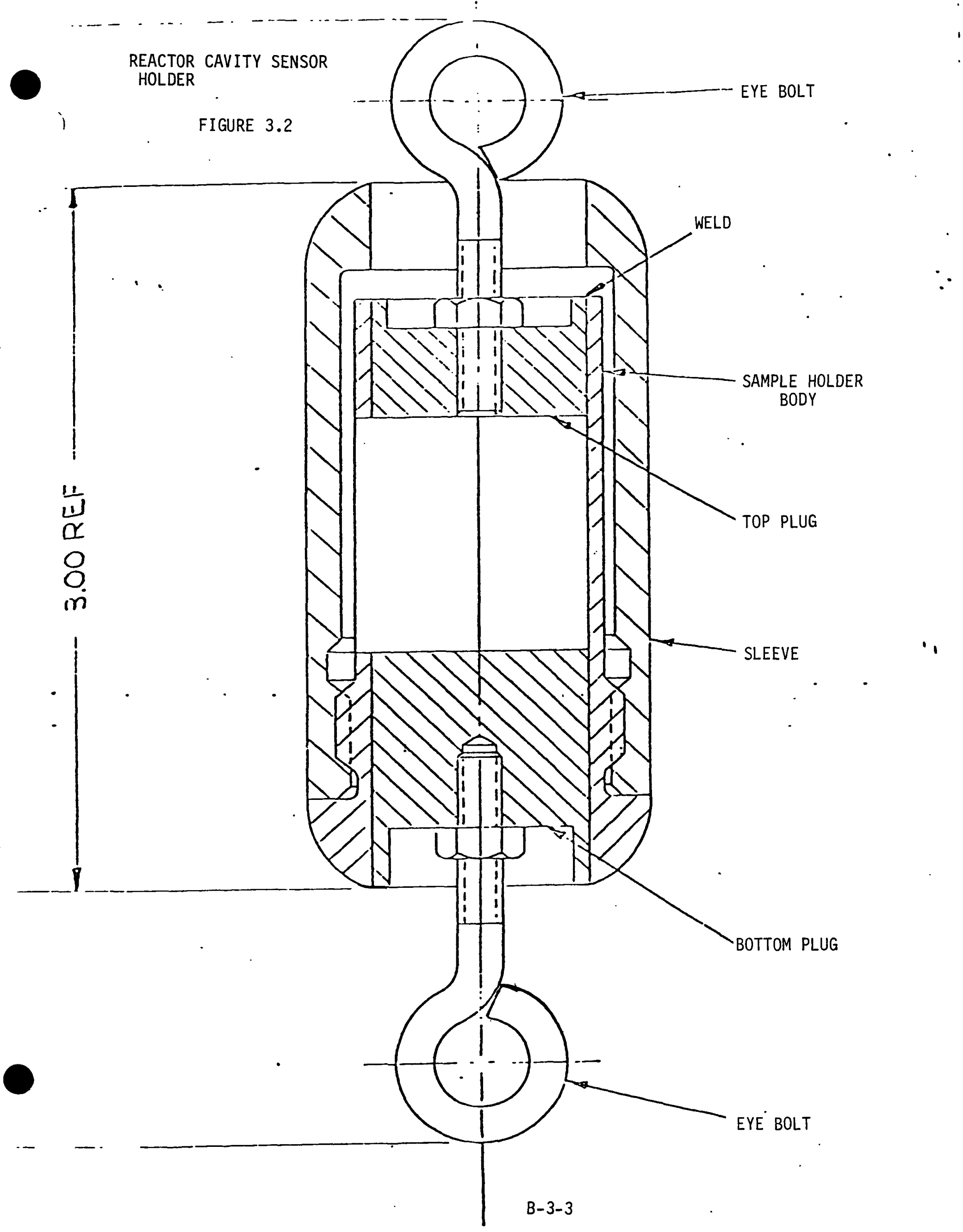


permits easy retrieval of the irradiated sensors while at the same time assuring integrity of the system during installation and removal.

\subsection{Proposed Experiment}

Two irradiations will be made in the reactor cavity. The first of these will be during the $4 \mathrm{~mW}$, one day of operation to irradiate the lower power characterizers. During this time, there will be no stored fuel in the In-Vessel Storage modules. The second irradiation will be made during the $400 \mathrm{~mW}$, eight day run for the high power characterizers. As indicated in Section 2.3, one of the IVS modules will contain fuel during the high power irradiation. Thus, the two measurements will provide the desired measurements of fluxes with and wi thout stored fuel.

During the low power irradiation, five capsules will be irradiated at elevations which correspond approximately to 18 feet, 12 feet and 6 feet above core midplane, at core midplane, and 6 feet below core midplane. The sensors in the capsules will include Solid State Track Recorders (SSTR's) with ${ }^{239} \mathrm{Pu}$ and $235 \mathrm{U}$, and radioactivants of tantalum, cobalt, nickel, iron, sodium and chromium. This array of sensors will provide information on the spectral distribution of the neutron flux as well as the intensity.

During the high power irradiation, five more capsules will be irradiated. These capsules will be located at the same elevations as those in the low power irradiation. There will be about three orders of magnitude more flux received by the sensors in the high power irradiation, requiring some adjustment in the array of sensors. Also, during the high power irradiation, some stored fuel will be located in the sector 2 IVS module, as illustrated in Figure 3.3. Also shown in Figure 3.3 is the relative position of the reactor cavity thimble in which these measurements are to be made. The azimuthal location of the thimble with respect to the storage modules will introduce additional complexity into interpretation of the results. 


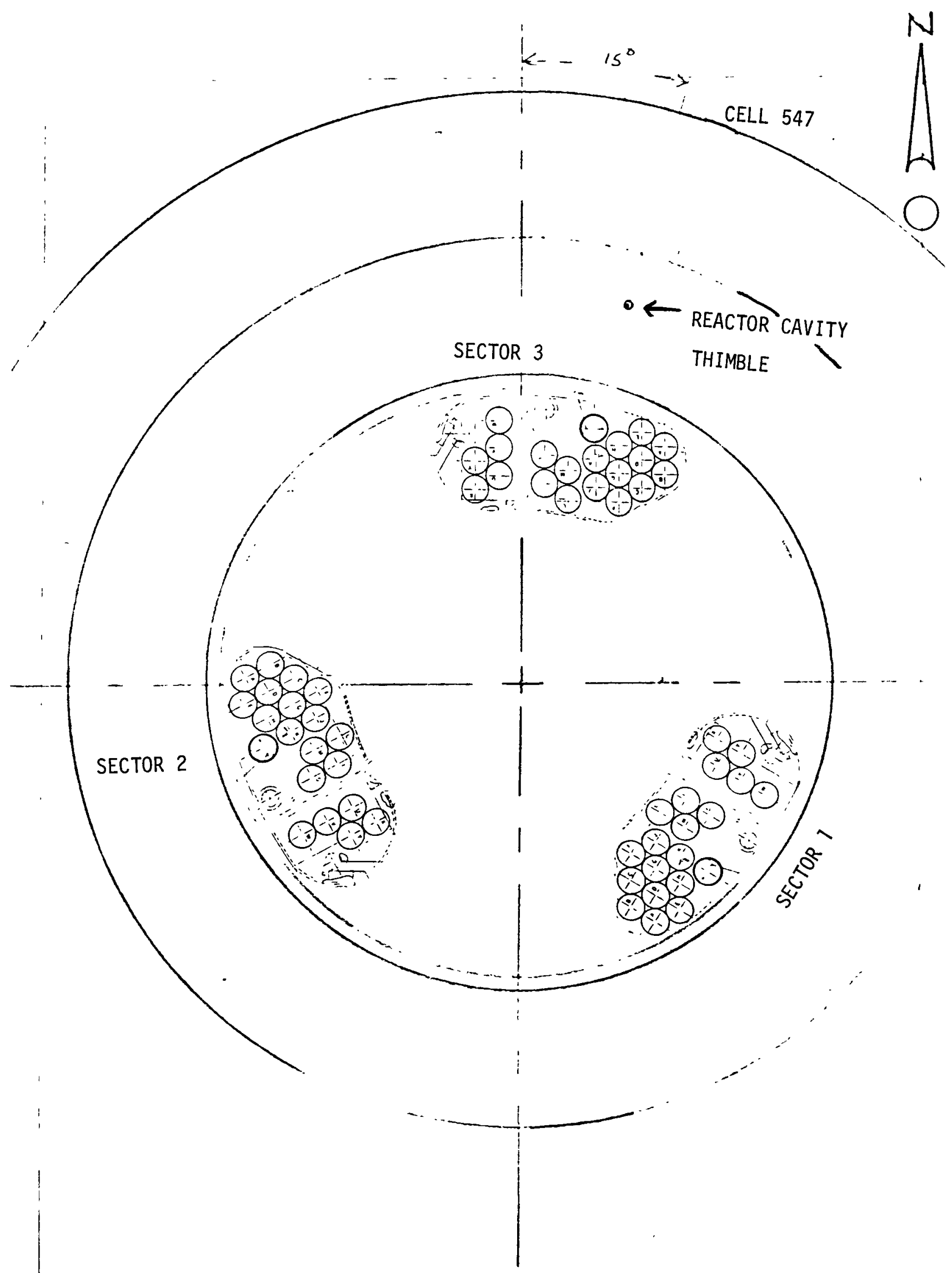

FIGURE 3.3 Location Of Storage Module With Respect To Reactor Cavity Thimble 


\subsection{Expected Results}

Two-dimensional ( $R-Z$ ) discrete ordinates calculations were made to support the design of the radial shield and the design of the reactor cavity shield and boron collar above the reactor guard vessel. The fluxes generated in these calculations were used as a basis for the design of sensor packages and provide a basis for the expected results. In addition to the difference in the neutron flux spectrum and intensity associated with the amount of stored fuel that is present, the reactor cavity measurements will provide an axial profile for comparison to the calculations. Comparatively little axial variation in the neutron flux is anticipated because of the large number of scatterings that can take place. The neutron flux is calculated to decrease by less than order of magnitude between the core midplane elevation and the top of the reactor cavity thimble.

\subsection{Acknowledgements}

Design and procurement of the sample holders for the reactor cavity measurements was by W. P. Stinson. 


\section{DISTRIBUTION}

DOE/RL (3)

JR Patterson II

Argonne National Laboratory Applied Physics Division Building 316 9700 South Cass Avenue Argonne, IL 60439

EF Bennett

HEDL (28)

$\begin{array}{ll}\text { RA Bennett } & \text { W/D-3 } \\ \text { WL Bunch (3) } & \text { W/D-1 } \\ \text { LL Carter } & \text { W/D-1 } \\ \text { TF Cillan } & \text { W/D-1 } \\ \text { JW Daughtry } & \text { W/D-2 } \\ \text { KD Dobbin } & \text { W/D-2 } \\ \text { DG Doran } & \text { W/A-57 } \\ \text { WN MCElroy } & \text { W/C-39 } \\ \text { FS Moore (3) } & \text { W/D-1 } \\ \text { RJ Morford } & \text { W/D-1 } \\ \text { CL Peckinpaugh } & \text { W/D-41 } \\ \text { JA Rawl ins } & \text { W/A-3 } \\ \text { F. Schmittroth } & \text { W/A-4 } \\ \text { WP Stinson } & \text { W/D-1 } \\ \text { EL Tang } & \text { W/D-1 } \\ \text { AD Wilcox } & \text { W/D-1 } \\ \text { DW Wootan } & \text { W/A-3 } \\ \text { Central Files (5) } & \text { W/C-110 } \\ \text { Publ. Services (2) } & \text { W/C-115 }\end{array}$

$W / D-1$

$W / D-1$

$W / D-2$

W/D-2

W/A-57

W/C-39

$W / D-1$

$W / D-1$

$W / D-41$

W/A-3

W/A-4

$W / D-1$

$W / D-1$

$W / D-1$

W/C-110

Publ. Services (2) W/C-115
DOE/RRT-HQ (3) NE-53

Program Division Director, B-107 PB Hemmig JW Lewellen

National Bureau of Standards Center of Radiation Research U. S. Department of Commerce Building 235 Washington, DC 20234

DM Gilliam

JA Grund 1

\section{ENd - 4-15-83}

